\title{
Selective Removal of Sodium Salt Taste Disrupts the Maintenance of Dendritic Architecture of Gustatory Relay Neurons in the Mouse Nucleus of the Solitary Tract
}

\author{
(ㄱ) Rolf Skyberg, Chengsan Sun, and Dovid L. Hill
}

https://doi.org/10.1523/ENEURO.0140-20.2020

Department of Psychology, University of Virginia, Charlottesville, VA 22904-4400

\begin{abstract}
Neuronal activity plays critical roles in the development of sensory circuits in the mammalian brain. Experimental procedures are now available to alter the function of specific taste transduction pathways and have been especially useful in studying how stimulus-specific taste activity influences the development of central gustatory circuits. We previously used a mouse knock-out (KO) model in which the transduction channel necessary for sodium taste is removed from taste bud cells throughout life. In these KO mice, the terminal fields that carry taste information from taste buds into the nucleus of the solitary tract (NST) fail to mature, suggesting that sodium-elicited taste activity is important for the proper development of central gustatory circuits. Here, we tested the hypothesis that the development and maintenance of the dendritic architecture of NST relay cells, the primary postsynaptic partner of gustatory nerve terminal fields, are similarly dependent on sodium-elicited taste activity. The dendritic fields of NST relay cells, from adult male and female mice in which the $\alpha$-subunit of the epithelial sodium channel $(\alpha \mathrm{ENaC})$ was conditionally deleted in taste bud cells throughout life, were up to $2.4 \times$ larger and more complex than that of age-matched control mice. Interestingly, these differences in dendritic architecture did not appear until after the age when terminal fields begin "pruning," after postnatal day $(\mathrm{P}) 20$. Overall, our results suggest that ENaC-mediated sodium taste activity is necessary for the maintenance of dendritic fields of relay cells in the gustatory NST.
\end{abstract}

Key words: activity dependent; dendritic maintenance; epithelial sodium channel; gustatory circuit; nucleus of the solitary tract; taste

\section{Significance Statement}

Neural activity plays major roles in the development of sensory circuits in the mammalian brain. Here, we tested whether loss of sodium taste activity throughout development impacts the dendritic development of cells that relay peripheral taste information to more central structures, in the nucleus of the solitary tract (NST). We found that the dendritic fields of NST relay neurons in mice without sodium taste activity throughout development increased in size at about the age that normal "pruning" occurs in gustatory nerve terminal fields. Our findings suggest a novel role for sodium taste activity in the maintenance of NST relay cell dendritic architecture and highlight a level of plasticity not seen in other sensory systems.

Received April 8, 2020; accepted July 27, 2020; First published August 14, 2020.

The authors declare no competing financial interests.
Author contributions: R.S. and D.L.H. designed research; R.S. and C.S. performed research; R.S., C.S., and D.L.H. analyzed data; R.S., C.S., and D.L.H. wrote the paper. 


\section{Introduction}

Neuronal activity plays important developmental roles in both subcortical and cortical sensory circuits (Brunjes, 1994; Cang et al., 2005; Lee, 2005; Leake et al., 2006; Guido, 2008; Sun et al., 2017). For instance, developing visual circuits in the dorsal lateral geniculate nucleus (dLGN) are shaped by both spontaneous and visuallyevoked activity in the retina (Katz and Shatz, 1996; Hooks and Chen, 2006). Removal of this activity has several effects on developing dLGN circuits in preventing the pruning of retinal ganglion cell terminal fields (Katz and Shatz, 1996; Stellwagen and Shatz, 2002), inhibiting synaptic refinement (Hooks and Chen, 2006), and altering both dendritic morphology and physiology of postsynaptic thalamocortical relay cells (Wiesel and Hubel, 1963; Friedlander et al., 1982). Thus, neural activity regulates multiple aspects of the developing visual pathway even at the first synaptic relay in the brain.

By comparison, less is known about roles neural activity play in developing subcortical gustatory circuits, areas important in regulating feeding and motivated behaviors (Spector and Travers, 2005; Spector and Glendinning, 2009). Terminal fields of nerves that carry gustatory information from taste buds to the brain undergo substantial activity-dependent refinement throughout early life, similar to developing retinogeniculate terminal fields in the dLGN (Katz and Shatz, 1996; Sun et al., 2017). Initially, chorda tympani (CT), greater superficial petrosal (GSP), and glossopharyngeal (IX) terminal fields in the rodent nucleus of the solitary tract (NST) are large and overlap extensively (Mangold and Hill, 2008). Throughout postnatal development these terminal fields are "pruned" into a smaller, more segregated organization (Sollars et al., 2006; Mangold and Hill, 2008; Zheng et al., 2014). This anatomic development occurs in tandem with a nearly two-fold developmental increase in the magnitude of salty-taste responses (and to a lesser extent sweet-taste responses) in the CT (Yamada, 1980; Hill and Bour, 1985; Hill, 1988; Zheng et al., 2014), suggesting increases in peripheral input regulates terminal field "pruning." Sun et al. (2017) confirmed this relationship by using mice in which the channel that transduces salty taste stimuli, the epithelial sodium channel (ENaC), was genetically deleted from taste bud cells throughout an animals' life [ENaC knockout (KO) mice; Chandrashekar et al., 2010; Sun et al., 2017]. These ENaC KO mice had significantly diminished CT and GSP nerve responses to $\mathrm{NaCl}$, did not exhibit normal appetitive licking behaviors to $\mathrm{NaCl}$, and had large, overlapping, unrefined CT and GSP terminal fields in adulthood (Chandrashekar et al., 2010; Sun et al., 2017). Interestingly, removal of ENaC activity in adulthood, after terminal fields reached maturity, reverts the terminal field

This work was supported by the Nation Institutes of Health Grant R01 DC000407 (to D.L.H.).

Correspondence should be addressed to David L. Hill at dh2t@virginia.edu. https://doi.org/10.1523/ENEURO.0140-20.2020

Copyright (C) 2020 Skyberg et al.

This is an open-access article distributed under the terms of the Creative Commons Attribution 4.0 International license, which permits unrestricted use, distribution and reproduction in any medium provided that the original work is properly attributed. organization to a large, overlapping, and immature state (Skyberg et al., 2017). Therefore, salt taste activity from a single transduction pathway is necessary for the proper development and for the maintenance of gustatory terminal fields in control mice.

Given the large effects that removing sodium salt taste has on gustatory terminal fields, one might expect removing ENaC-mediated neural activity would also affect their postsynaptic targets that send afferent taste information to more central structures. A few studies suggest a role for taste activity in the development of dendritic architecture of NST relay cells, the primary postsynaptic partners of gustatory terminal field; however, these studies have not shown this conclusively (Lasiter and Kachele, 1990; Lasiter, 1991). To test this hypothesis directly, we examined the development of dendritic size, shape, and spread in postnatal day (P)2O and adult control and ENaC KO male and female mice. Our results show that NST relay cell dendritic architecture in normally-developing and $\mathrm{ENaC} \mathrm{KO}$ mice reaches maturity by P20. This age is before sodium salt taste activity fully matures in controls. Unexpectedly, we found that the size of dendritic fields in ENaC KO mice became larger and more complex than controls with age, while the general shape of the dendritic fields remained similar to controls. Our surprising findings indicate that, while ENaC-mediated sodium salt taste activity appears not to be involved in the normal dendritic development of NST relay cells in control mice, it is required to maintain their mature dendritic organization.

\section{Materials and Methods}

\section{Animals}

All experiments were approved by the University of Virginia Animal Care and Use Committee and followed guidelines set forth by the National Institutes of Health and the Society for Neurosciences. To examine the role of sodium salt taste on the development and organization of gustatory relay cell dendrites in the rostral NST, we used mice described in detail by Chandrashekar et al. (2010). Briefly, the $\alpha$-subunit of the $\mathrm{ENaC}(\alpha \mathrm{ENaC})$ was conditionally deleted in taste bud cells by crossing mice that drove the expression of Cre-recombinase under the cytokeratin 19 (CreK19) promotor with mice that were homozygous for the floxed Scnn1a ( $\alpha \mathrm{ENaC})$ gene (Scnn1 $\left.\mathrm{a}^{\text {flox/flox }}\right)$. The CreK19 mice were generously supplied by Charles Zuker and Edith Hummler supplied the Scnn1a flox/flox mice. Therefore, our experimental animals had the genotype K19-Cre Scnn1a flox/flox $(\alpha \mathrm{ENaC} \mathrm{KO})$. The control group consisted of mice that were littermates to experimental animals, but did not have the CreK19 promoter $\left(S c n n 1 a^{f l o x / f l o x}\right)$. To investigate the morphologic development of dendrites, we retrogradely labeled relay cells in the NST at two significant developmental ages. First, we labeled NST relay cells in control and $\alpha \mathrm{ENaC} \mathrm{KO}$ mice between P18 and P22 (P20 controls, four mice, two male/ two female, 22 cells; P20 $\alpha \mathrm{ENaC} \mathrm{KO}$, three mice, two male/one female, 31 cells). We chose this age group for three reasons. At this age taste responses to $\mathrm{NaCl}$ have not fully matured (Hill and Bour, 1985; Zheng et al., 2014), 

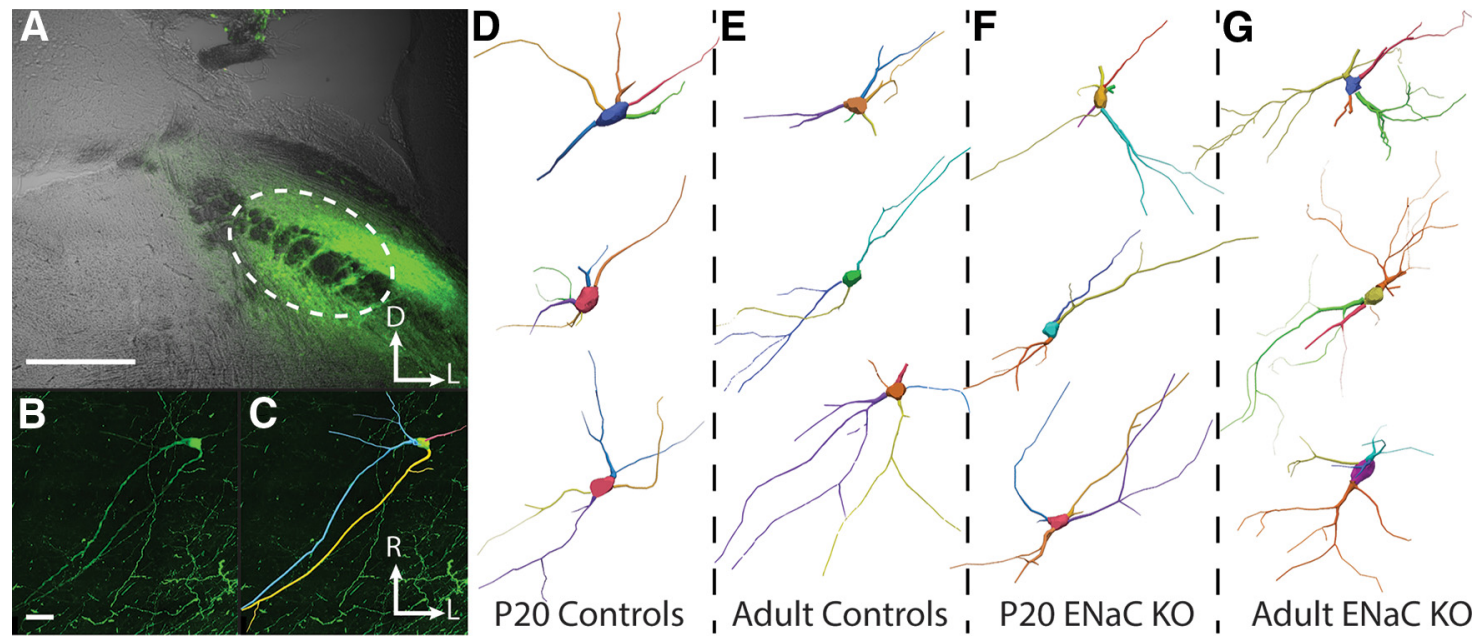

Figure 1. Retrograde labeling and tracing of NST relay cells. $\boldsymbol{A}-\boldsymbol{C}$, Stereotaxic injections into the waist region of the PBN results in robust retrograde labeling of relay cells in the NST. $\boldsymbol{A}$, Coronal section through the PBN showing a stereotaxically-guided injection of $10 \%$ BDA (green) into the waist region of the right PBN (outlined with white dotted line). Photomicrograph taken at 4x. Scale bar in $A, 500 \mathrm{~mm}$. D, dorsal; L, lateral. $B$, Horizontal section through the right NST showing a retrogradely-labeled NST relay cell following an injection of $10 \%$ BDA into the right PBN. Photomicrograph taken at 60x. C, Tracing of the same NST relay cell shown in B. R, rostral; L, lateral. $\boldsymbol{D}-\boldsymbol{G}$, Representative NST relay cell tracings from P20 control $(\boldsymbol{D})$, adult control $(\boldsymbol{E}), \mathrm{P} 20 \mathrm{ENaC} \mathrm{KO}(\boldsymbol{F})$, and adult ENaC KO mice (G). Scale bar in $\boldsymbol{B}, 20 \mathrm{~mm}$ and also applies to $\mathbf{C}-\mathbf{G}$.

allowing us to assess how dendritic morphologies are organized before peripheral taste input to the NST has matured. The terminal fields of gustatory nerves in the NST begin their developmental pruning around this time, suggesting this is a period when substantial functional and structural reorganization within the NST occurs (Sollars et al., 2006; Mangold and Hill, 2008; Zheng et al., 2014). And finally, animals younger than P18 were too small to reliably fit into the stereotaxic device, making consistent targeting of the parabrachial nucleus (PBN; the next central relay beyond the NST) difficult. We also labeled NST relay cells in control and $\alpha \mathrm{ENaC} \mathrm{KO}$ mice between 60 and $120 \mathrm{~d}$ of age (adult control, eight mice, three male/five female, 123 cells; adult $\alpha \mathrm{ENaC} \mathrm{KO}, 10$ mice, four male/six female, 81 cells). At these ages, both the peripheral taste responses and gustatory terminal fields in the NST are fully matured in control mice (Sollars et al., 2006; Mangold and Hill, 2008; Zheng et al., 2014; Sun et al., 2017). There were no sex-related differences found in any of our experiments or analyses; therefore, male and female mice within the same experimental group were combined.

\section{PBN injections}

To selectively label NST relay cells, we injected the retrograde tracer biotinylated dextran amine (BDA; Invitrogen; D7135) into the "waist" region of the PBN (Fig. $1 A)$. This area is the primary target for NST relay cell axons and retrograde tracer injections here result in Golgi-like labeling of relay cells in the NST (Fig. 1B-G; Norgren and Leonard, 1971; Norgren and Pfaffmann, 1975; Whitehead, 1990; Tokita et al., 2009; Tokita and Boughter, 2016). Mice were sedated with a $0.32 \mathrm{mg} / \mathrm{kg}$ $(0.24 \mathrm{mg} / \mathrm{kg}$ for P20 mice) injection of Domitor (medetomidine hydrochloride, i.m.; Pfizer Animal Health) and anesthetized with $40 \mathrm{mg} / \mathrm{kg}$ ( $30 \mathrm{mg} / \mathrm{kg}$ for P20 mice) Ketaset (ketamine hydrochloride, i.m.; Fort Dodge Animal Health). A water-circulating heating pad was used to maintain body temperature. Mice were placed in a non-traumatic head holder (Erickson, 1966), and an incision was made along the midline on the top of the head to expose the animal's skull. Bregma and $\lambda$ were aligned horizontally and two $2 \times 2-\mathrm{mm}$ bilateral holes were drilled in the skull $\sim 5.2 \mathrm{~mm}(5.1 \mathrm{~mm}$ for P20 mice) caudal to bregma and $1.2 \mathrm{~mm}(1.1 \mathrm{~mm}$ for P20 mice) lateral to the midline (similar to Tokita et al., 2009; Tokita and Boughter, 2016). A glass pipette filled with 10\% 3 $\mathrm{kDa} \mathrm{BDA}$ in $0.1 \mathrm{~m}$ citrate/ $\mathrm{NaOH}$ buffer $(\mathrm{pH} 3.0)$ was slowly lowered $2.8 \mathrm{~mm}$ (2.7 mm for P20 mice) from the top of the cerebellum. This acidic solvent increased retrograde axonal uptake of the tracer and provided Golgi-like cell labeling in the NST (Fig. 1; Kaneko et al., 1996; Reiner et al., 2000; Corson and Erisir, 2013). BDA was injected iontophoretically with a $6-\mu \mathrm{A}$ positive current $(7 \mathrm{~s}$ on, $7 \mathrm{~s}$ off) for $10 \mathrm{~min}$ (Reiner et al., 2000; Fekete et al., 2015). Following the injection, the pipette tip was left in place without any positive current for 5 min to allow time for tracer uptake and to reduce backflow through the injection site. The pipette was then slowly raised out of the brain and the procedure was repeated on the other side of the brain. The animal's scalp was then sutured or sealed using Vetbond and the animal was injected with $5 \mathrm{mg} /$ $\mathrm{ml}(3.75 \mathrm{mg} / \mathrm{ml}$ for P20 mice) Antisedan (atipamezole hydrochloride, i.m.; Pfizer Animal Health) to promote reversal of anesthesia.

\section{CT nerve label}

Procedures used to label the CT terminal field with fluorescent tracers were similar to that described previously in mouse (Sun et al., 2015, 2017; Skyberg et al., 2017). Briefly, $24 \mathrm{~h}$ after PBN injections, animals were anesthetized as described above, placed into a non-traumatic head holder (Erickson, 1966) and maintained at $36^{\circ} \mathrm{C}$ with 
a water-circulating heating pad. The animal was placed into the supine position and an incision was made along the ventral midline of the neck. Musculature was retracted to expose the right tympanic bulla. The bulla was opened and the CT was cut peripheral to the geniculate ganglion. Crystals of 3$\mathrm{kDa}$ tetramethyrhodamine dextran amine (TMR; Thermofisher Scientific; D3308, RRID: AB_2315472) were placed on the central stump of the CT, and the opening of the bulla was filled with Kwik-Sil (World Precision Instruments) to prevent crystals from diffusing from the site of the intended label. The incision was then sutured and the animal was revived using Antisedan (atipamezole hydrochloride, i.m.; Pfizer Animal Health).

\section{Tissue preparation}

Following a 48-h survival period, animals were deeply anesthetized with urethane and transcardially perfused with Krebs-Henseleit buffer ( $\mathrm{pH} 7.3$ ), followed by $4 \%$ paraformaldehyde ( $\mathrm{pH}$ 7.2). Brains were removed, postfixed in $4 \%$ paraformaldehyde overnight, and sectioned horizontally on a vibratome at $100 \mu \mathrm{m}$. We chose to section tissue in the horizontal plane, as the dendritic arbors run parallel to this plane of sectioning, thus reducing the number of transected dendrites. It is also the plane in which the gustatory nerve axons branch from the solitary tract and project medially (Davis and Jang, 1988; Whitehead, 1988; Lasiter et al., 1989). Sections were then incubated in PBS containing $0.4 \%$ Triton $\mathrm{X}-100$ for $1 \mathrm{~h}$ and then placed in PBS containing $0.2 \%$ Triton X-100 with $1: 400$ streptavidin Alexa Fluor 488 (Jackson ImmunoResearch; 016-540-084, RRID: AB_2315383) for $2 \mathrm{~h}$ to visualize the BDA-filled NST relay cells. The CT terminal fields were labeled with TMR and did not require further processing for visualization. Sections were mounted onto gel-coated slides and coverslipped with Vectashield Hard Mounting Medium (Vector Laboratories).

To verify our stereotaxic injection parameters, one mouse from each group was injected and processed as described above. However, these brains were sectioned coronally at $100 \mu \mathrm{m}$ to allow for viewing of the injection tract as well as the center of the injection (Fig. 1A).

\section{Confocal microscopy}

Tissue was imaged using a Nikon 80i microscope fitted with a Nikon C2 scanning system (Nikon Instruments, Inc.). NST relay cells were located and imaged using a $10 \times$ objective (Nikon, CFIPlanApo; NA $=0.45$ ) followed by a higher-resolution image taken with a $63 \times$ oil-immersion objective (Nikon, PlanApo VC; NA=1.4). The fluorescent labels were matched to the wavelengths of the respective lasers used to image the tissue (argon laser $-488 \mathrm{~nm}, 10$ $\mathrm{mW}$, NST relay cells; DPSS laser $-561 \mathrm{~nm}, 10 \mathrm{~mW}, \mathrm{CT}$ ). Sequential optical sections were captured every $1 \mu \mathrm{m}$ through the extent of every imaged cell. Images were obtained with settings adjusted so that pixel intensities were near (but not at) saturation.

\section{Data analysis}

Confocal images were imported into Neurolucida 11.11.12 (MBF Bioscience; RRID:SCR_001775) and reconstructions were made by tracing the dendritic architecture and cell bodies throughout the $z$-stack. These tracings were then opened in Neurolucida Explorer 2.7 (MBF Bioscience; RRID:SCR_001775), and measures were taken on the dendritic architecture of each retrogradely-filled NST relay cell tracing. These measures included the number of primary dendrites, number of dendritic branch points, number of dendritic endings, dendritic length, mean dendritic length, and the dendritic complexity index $(\mathrm{DCl})$. The $\mathrm{DCl}$ was determined from the following equation, $\mathrm{DCl}=$ (sum of branch tip order + number of dendritic endings) $\times$ (total dendritic length/number of primary dendrites) (Pillai et al., 2012).

In addition to collecting basic measures of dendritic architecture, we also performed Sholl analyses (Sholl, 1956) on each of the traced NST relay cells using Neurolucida Explorer 2.7 (MBF Bioscience; RRID:SCR_001775). A series of concentric rings were placed over the traced neuron, centered on the cell body. The centermost ring had a diameter of $20 \mu \mathrm{m}$ (the diameter of the largest possible NST relay cell soma) while each of the concentric rings successively increased their diameter by $5 \mu \mathrm{m}$.

Finally, we calculated a polar histogram for each traced cell using Neurolucida Explorer 2.7 (MBF Bioscience; RRID:SCR_001775). This technique displays the length and direction of dendritic processes in a two-dimensional format. These polar histograms show the total length of dendrites present within $20^{\circ}$ bins, covering $360^{\circ}$ in the horizontal plane. To normalize for the angle that horizontal brain sections were mounted onto slides, a straight line was drawn from the bottom to the top of the fourth ventricle (or along the midline whenever the ventricle was not present). Representative tracings were then rotated as needed until the line was oriented vertically. We then reflected all cells from the left NST $180^{\circ}$ horizontally (i.e., along the rostral-caudal axis of the brain). The resulting datasets were a collection of cells from the left and the right NST.

\section{Analysis of relay cells along the dorsal-ventral axis of the NST}

To assess and compare the distributions of relay cells within the NST, we recorded and plotted the location of a majority of the retrogradely-filled relay cells (231 of 257) onto representative horizontal brainstem tracings. We were not able to reliably analyze the location of 26 relay cells because of significant degradation of the tissue. To be consistent with previous literature, cells were grouped into four zones based on the dorsal-ventral axis of the NST in which they were located. The landmarks used to define these four zones were similar to what has been reported previously in mouse (Sun et al., 2015, 2017; Skyberg et al., 2017) and rat (King and Hill, 1991; Krimm and Hill, 1997; May and Hill, 2006; Sollars et al., 2006; Mangold and Hill, 2008; Corson and Hill, 2011). The first zone, the far dorsal zone of the NST, is characterized by sections with a relatively large fourth ventricle, a small solitary tract in the rostral portion of the NST, and by a lack of the hypoglossal and facial nucleus. The far dorsal zone is located between 100 and $300 \mu \mathrm{m}$ from the surface of 


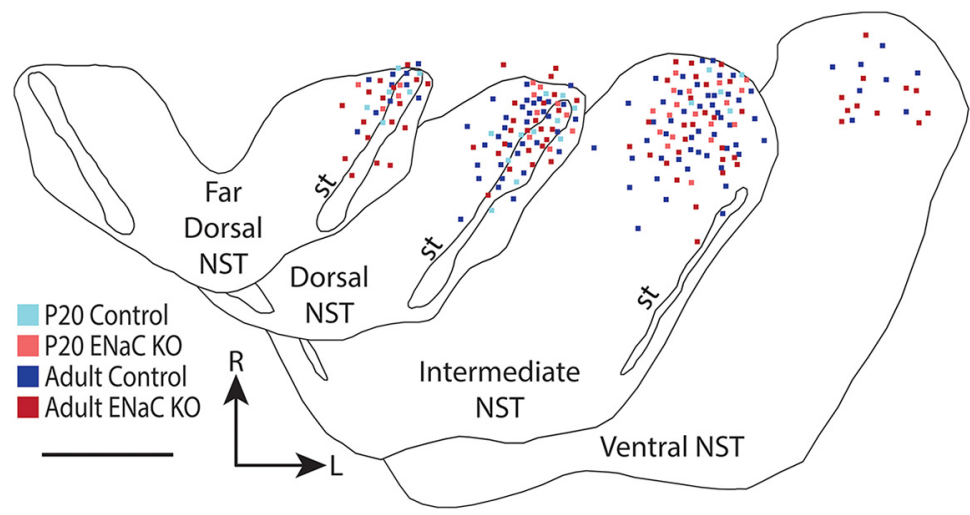

Figure 2. Relay cell locations throughout the dorsal ventral axis of the NST. The location of each cell from P20 control (light blue), adult control (dark blue), P20 ENaC KO (light red), and adult ENaC KO (dark red) mice are projected onto representative tracings of the horizontally-sectioned NST. The far dorsal, dorsal, intermediate, and ventral NST were located 100-300mm, 300-500mm, 500$800 \mathrm{~mm}$ and $800-1200 \mathrm{~mm}$ from the surface of the brainstem, respectively. Scale bar, $500 \mathrm{~mm}$; NST, nucleus of the solitary tract; st, solitary tract; $\mathrm{R}$, rostral; L, lateral.

the brainstem in mouse (Fig. 2). The dorsal zone also contains the fourth ventricle but, in these sections, it does not extend as far in the medial-lateral plane as in the far dorsal zone. Sections from the dorsal zone have an NST that extends more rostrally than in the far dorsal zone, a solitary tract that occupies nearly the entire rostral-caudal extent of the NST, and the presence of the dorsal cochlear nucleus. The dorsal zone is immediately dorsal to the hypoglossal nucleus and is located roughly $300-500 \mu \mathrm{m}$ from the surface of the brainstem (Fig. 2). The intermediate zone is characterized by a significant thinning of the fourth ventricle compared with the far dorsal and dorsal zones, the solitary tract is thinner and shorter than seen in the dorsal zone, the rostral pole of the NST extends further anteriorly than in the dorsal zone, and both the hypoglossal and facial nuclei are evident. The intermediate zone is located around 500 and $800 \mu \mathrm{m}$ from the surface of the brainstem (Fig. 2). The ventral zone is at a level immediately ventral to the fourth ventricle, the NST is less defined and narrow at its rostral-most extent compared with more dorsal zones, the ventral cochlear nucleus is apparent, and the hypoglossal and facial nuclei are evident. The ventral zone contains the remainder of the NST and is located roughly 800 and $1200 \mu \mathrm{m}$ from the surface of the brainstem (Fig. 2). It should be noted that the NST is oriented within the brainstem with the caudal-most portion of the NST positioned dorsal to the rostral-most portion of the NST (Ganchrow et al., 2014). That is, the NST extends rostrally and ventrally from the caudal-most extent of the NST. Therefore, the far dorsal zone more accurately represents the dorsal-caudal portion of the NST and the ventral zone represents the ventral-rostral portion of the NST.

\section{CT nerve neurophysiology}

To establish that KO of the Scnn1a gene in the tongue resulted in reduced functional $\mathrm{CT}$ responses to $\mathrm{NaCl}$ and to determine the normal development of $\mathrm{ENaC}$ function in control mice, we recorded taste-stimulus-evoked wholenerve activity from the CT of each group of mice using methods described previously (Sun et al., 2015, 2017;
Skyberg et al., 2017). Briefly, mice were anesthetized as described for the retrograde parabrachial injection procedure. The animals were then tracheotomized and placed on a circulating water heating pad to maintain body temperature. Hypoglossal nerves were transected bilaterally to prevent tongue movement, and the mouse was placed in a nontraumatic head holder. The left CT nerve was isolated using a mandibular approach. The nerve was exposed near the tympanic bulla, cut, desheathed, and positioned on a platinum electrode. A second electrode was placed in nearby muscle to serve as a reference. Kwik-Sil (World Precision Instruments) was placed in the cavity around the nerve to maintain a highly functioning preparation.

\section{Stimulation procedure}

All chemicals were reagent grade and prepared in artificial saliva (Hellekant et al., 1985). Neural responses from the CT were recorded to ascending concentrations series of $0.05,0.1,0.25$, and $0.5 \mathrm{~m} \mathrm{NaCl}$ to assess the taste responses to prototypical stimuli that represent salty to humans. Concentration series were bracketed by applications of $0.5 \mathrm{M} \mathrm{NH}_{4} \mathrm{Cl}$ to monitor the stability of each preparation and for normalizing taste responses. Solutions were applied to the tongue in $5 \mathrm{ml}$ aliquots with a syringe and allowed to remain on the tongue for $\sim 20 \mathrm{~s}$. We used this period of stimulation so that we could measure the steady state responses. After the application of each solution, the tongue was rinsed with artificial saliva for $\geq 1$ min (Hellekant et al., 1985). This period allowed a full recovery of neural responses (i.e., the responses were not adapted by previous responses; Shingai and Beidler, 1985). In addition, responses to the $\mathrm{NaCl}$ concentration series were recorded in presence of the $\mathrm{ENaC}$ blocker, amiloride $(50 \mu \mathrm{M})$. Rinses during this series were with amiloride in artificial saliva.

All responses were calculated as follows: the average voltage of the spontaneous activity that occurred for the second before stimulus onset was subtracted from the voltage that occurred from the period from the first to sixth second after stimulus application. Response magnitudes were then expressed as ratios relative to the mean 
of $0.5 \mathrm{M} \mathrm{NH}_{4} \mathrm{Cl}$ responses before and after taste stimulation. Whole-nerve response data were retained for analysis only when $0.5 \mathrm{M} \mathrm{NH}_{4} \mathrm{Cl}$ responses that bracketed a concentration series varied by $<10 \%$.

\section{Experimental design and statistical analyses}

All measurements presented are given as means ( \pm SEM). Prism 7 (GraphPad; RRID:SCR_002798) was used for quantification and statistical analysis.

\section{Measurements of NST relay cell location and dendritic morphology}

Experiments investigating NST relay cell dendritic architecture were conducted in control and $\alpha \mathrm{ENaC} \mathrm{KO}$ mice at P18-P22 (P20 control, four mice, two male/two female; P20 $\alpha \mathrm{ENaC} \mathrm{KO}$, three mice, two male/one female) and P60-P120 (adult control, eight mice, three male/five female; adult $\alpha \mathrm{ENaC} \mathrm{KO}, 10$ mice, four male/six female). Neurons collected from different mice within the same age $\times$ experimental group were collapsed into a single group, resulting in four larger neural populations (22 cells from P20 control mice, 31 cells from P20 $\alpha \mathrm{ENaC} \mathrm{KO}$ mice, 123 cells from adult control mice, 81 cells from adult $\alpha \mathrm{ENaC} \mathrm{KO}$ mice). The $\chi^{2}$ test was used to compare the proportion of bipolar and multipolar cells in both animal groups at each age as well as to compare the distribution of relay cells along the dorsal-ventral axis of the NST between control and $\alpha \mathrm{ENaC} \mathrm{KO}$ mice at both ages. A one-way ANOVA was used to statistically compare measures of dendritic architecture (number of primary dendrites, number of dendritic branches, total dendritic length, dendritic complexity) between control and $\alpha \mathrm{ENaC} \mathrm{KO}$ mice at P2O and adulthood. To statistically compare the mean frequency and mean length of each order of dendrite between control and $\alpha \mathrm{ENaC} \mathrm{KO}$ mice at P20 and adulthood, a two-way ANOVA was used (four groups $\times$ seven dendritic orders). Two-way ANOVAs were also used to compare measurements collected from Sholl analyses of cells from control and $\alpha \mathrm{ENaC} \mathrm{KO}$ mice at P20 and adulthood (four group $\times 47$ distances from cell soma). We used the Bonferroni procedure to adjust the $\alpha$ level for multiple comparisons (Armstrong, 2014); $p \leq 0.05$ were regarded as statistically significant.

\section{Total CT terminal field volumes}

Experiments inspecting the total CT terminal field volume were done in control and $\alpha \mathrm{ENaC}$ KO mice at P20 (P20 control, six mice, three male/three female; P20 $\alpha \mathrm{ENaC} \mathrm{KO}$, three mice, three male/0 female) and P60P120 (adult control, seven mice, three male/four female; adult $\alpha \mathrm{ENaC} \mathrm{KO}$, six mice, four male/two female). The mean ( \pm SEM) total CT terminal field volume was calculated for control and $\alpha \mathrm{ENaC} \mathrm{KO}$ mice at P20 and adulthood, and a one-way ANOVA was used to statistically compare these means. The Bonferroni procedure was used to adjust the $\alpha$ level for multiple comparisons (Armstrong, 2014), and only $p \leq 0.05$ was considered to be statistically significant.

\section{CT whole-nerve neurophysiology}

Experiments examining CT whole-nerve taste responses were done in control and $\alpha \mathrm{ENaC} \mathrm{KO}$ mice at P20 (P20 control, three mice, two male/one female; P20 $\alpha \mathrm{ENaC} \mathrm{KO}$, two mice, one male/one female) and P60P120 (adult control, five mice, three male/two female; adult $\alpha \mathrm{ENaC} \mathrm{KO}$, three mice, one male/two female). Due to the small number of observations in each group, we did two statistical tests that are most appropriate for these types of comparisons. For both tests, we focused on group- and age-related differences at $0.25 \mathrm{M} \mathrm{NaCl}$ and $0.5 \mathrm{M} \mathrm{NaCl}$. Taste responses to lower concentrations showed no differences between control and $\mathrm{ENaC} \mathrm{KO}$ mice at either age. First, we compared mean ( \pm SEM) relative $\mathrm{CT}$ responses to $0.25 \mathrm{M}$ and $0.5 \mathrm{M} \mathrm{NaCl}$ (normalized to $0.5 \mathrm{M} \mathrm{NH} 4 \mathrm{Cl}$ responses) between $\mathrm{P} 20$ control and P2O ENaC KO mice and between adult control and adult $\mathrm{ENaC} \mathrm{KO}$ mice with multiple t-tests, and with the alpha level (0.05) corrected by the Holm-Sidak correction method. We also did the Mann-Whitney nonparametric test for the same comparisons. Both statistical methods provided the same outcome. We present only the statistical findings from the multiple t-test comparisons.

\section{Results}

BDA injections into the waist region of the PBN resulted in Golgi-like, retrograde labeling of relay cells in the NST (Fig. 1). For the relay cells from the P20 control mice $(n=22)$, only two cells $(9.10 \%)$ were bipolar, while $20(90.9 \%)$ were multipolar. Similarly, of the 123 relay cells from adult control mice, only $16(13.0 \%)$ were bipolar while 107 cells $(87.0 \%)$ were multipolar. The relay cell populations in P20 $\alpha \mathrm{ENaC} \mathrm{KO}$ and adult $\alpha \mathrm{ENaC} \mathrm{KO}$ mice had similar proportions of bipolar and multipolar cells as the control sample. Of the relay cells from P20 $\alpha \mathrm{ENaC}$ KO mice $(n=31)$, three cells $(9.70 \%)$ were bipolar while 28 cells $(90.3 \%)$ were multipolar. Of the 81 relay cells from adult $\alpha \mathrm{ENaC} \mathrm{KO}$ mice, six (7.40\%) were bipolar and the remaining $75(92.6 \%)$ were multipolar. Statistical analysis using $\chi^{2}$ analysis confirmed that the distribution of bipolar and multipolar cells in all four groups were not statistically different from each other $\left(\chi^{2}(3)=1.72, p=0.634\right)$. These distributions were comparable to what has been reported in another study of rodent NST relay cell morphologies (Corson and Erisir, 2013). See Figure 1D-G for representative cell tracings from P20 control (Fig. 1D), adult control (Fig. 1E), P20 $\alpha \mathrm{ENaC} \mathrm{KO}$ (Fig. 1F), and adult $\alpha \mathrm{ENaC} \mathrm{KO}$ mice (Fig. 1G).

There was variability in the number of labeled cells that we were able to collect from each mouse, especially within the adult control group (Extended Data Fig. 3-1A) Despite this variability, a one-way ANOVA did not find a significant difference in the average number of cells labeled between groups Extended Data Fig. 3-1A, $F_{(3,24)}=2.849, p=0.062 ;$ ). We note that this statistical test was near but not at the threshold for statistical significance.

\section{Distribution of relay cells within the NST along the dorsal-ventral axis}

Figure 2 shows the location of 231 of the 257 retrogradely-labeled relay cells in the NST, as defined with horizontal sections (Sun et al., 2015, 2017; Skyberg et al., 
2017). Relay cells were located throughout the dorsal ventral axis of the NST. Approximately $37(16.0 \%)$ cells, regardless of group, were located in the far dorsal zone of the NST. The dorsal and intermediate zones contained a large majority of retrogradely-labeled relay cells, 77 $(33.3 \%)$ cells and $98(42.4 \%)$ cells, respectively. Finally, the ventral zone only contained 19 (8.30\%) retrogradely-labeled cells. This distribution reflects the relative percentage of terminal field label from the CT in control mice (Zheng et al., 2014; Skyberg et al., 2017; Sun et al., 2017).

The dorsal-ventral distribution of relay cells from adult control mice was not significantly different from adult ENaC KO mice $\left(\chi^{2}(3)=7.44, p=0.06\right)$. However, when we compared the dorsal-ventral distribution of relay cells from the P20 control population with that of the adult control distribution, we found a statistically significant difference $\left(\chi^{2}(3)=9.89, p=0.02\right)$. The distribution of relay cells from P20 control mice was shifted to the far dorsal (27.0\% in P20 controls vs $13.0 \%$ in adult controls) and dorsal (50.0\% P20 controls vs $29.0 \%$ in adult controls) sections when compared with that in adult control mice. The distribution in P20 control mice also did not have relay cells in the ventral sections of the NST, skewing the distribution toward the dorsal sections. Thus, relay cells from the P20 and adult control populations were distributed differently along the dorsal-ventral axis of the NST, suggesting an alteration in the region-specific projection pattern from the NST to the PBN throughout development. However, this may also be because of the large differences in the number of cells in each of these control groups. Finally, the dorsal-ventral distribution of P20 $\mathrm{ENaC} \mathrm{KO}$ relay cells was not significantly different from that of the adult ENaC KO group $\left(\chi^{2}(3)=3.24, p=0.356\right)$. Thus, despite the large differences in the number of cells in these two neuronal populations in $\mathrm{ENaC} \mathrm{KO}$ mice, they are sampled similarly along the dorsal-ventral axis of the NST (Fig. 2).

\section{Relay cells from adult $\alpha \mathrm{ENaC}$ mice have more complex dendritic fields}

There were no significant differences between the mean $( \pm S E M)$ number of primary dendrites of relay cells among P20 control $(4.05 \pm 0.3)$, adult control (3.72 \pm 0.1$)$, $\mathrm{P} 20 \alpha \mathrm{ENaC} \mathrm{KO}(3.65 \pm 0.7)$, and adult $\alpha \mathrm{ENaC} \mathrm{KO}(4.12 \pm$ $0.2)$ mice $\left(F_{(3,253)}=1.15, p=0.330\right.$; Fig. $\left.3 A\right)$. Likewise, the mean number of primary dendrites of only the multipolar cells in each group was not significantly different among these groups $\left(F_{(3,226)}=1.78, p=0.151\right.$; data not shown). Thus, the number of primary dendrites of NST relay cells did not change throughout development and was not influenced by the absence of sodium taste activity during development.

While the number of primary dendrites was not affected by the removal of ENaC-mediated sodium taste activity, we found that the number of dendritic branch points was affected. The mean ( \pm SEM) number of branch points was 1.6-1.8 $\times$ greater in cells from adult $\alpha \mathrm{ENaC} \mathrm{KO}$ mice (7.30 \pm 0.5$)$ compared with cells from P20 control $(4.41 \pm 0.6)$, adult control $(4.09 \pm 0.3)$, and P20 $\alpha \mathrm{ENaC}$
$\mathrm{KO}$ mice $(4.52 \pm 0.8)$. This difference was significant $\left(F_{(3,253)}=11.5, p<0.0001\right.$; Fig. $\left.3 B\right)$. The mean number of dendritic branch points of relay cells from P20 control, adult control, and P20 $\alpha \mathrm{ENaC} \mathrm{KO}$ mice were not significantly different from each other $(p>0.05$; Fig. $3 B)$. Therefore, the variability in the mean number of dendritic branch points of all neurons among individual mice is not responsible for the significant group-related differences we report for dendritic branch points (Extended Data Fig. 3-1B).

Similar to the number of dendritic branch points, the total dendritic length of relay cells from adult $\alpha \mathrm{ENaC} \mathrm{KO}$ mice was significantly greater than that of any other group $\left(F_{(3,253)}=9.59, p<0.0001\right.$; Fig. $\left.3 C\right)$. The mean $( \pm$ SEM) dendritic length $(\mu \mathrm{m})$ in cells from adult $\alpha \mathrm{ENaC} \mathrm{KO}$ $(692.76 \mu \mathrm{m} \pm 43.0)$ mice was 1.5-1.6x larger than that of cells from P20 control $(441.51 \mu \mathrm{m} \pm 39.4)$, adult control $(457.29 \mu \mathrm{m} \pm 24.7)$ and P20 $\alpha \mathrm{ENaC}$ KO mice (448.95 $\mu \mathrm{m} \pm 80.6)$. The mean dendritic length in relay cells in P20 control, adult control, and P20 $\alpha \mathrm{ENaC} \mathrm{KO}$ mice were not different from each other $(p>0.05$; Fig. $3 C)$. Calculating the mean dendritic length of all neurons from any one mouse illustrates that, while there is some variability from animal to animal, the significant differences we report are not due solely to one or two animals (Extended Data Fig. 3-1C).

These large differences in the mean dendritic length and number of dendritic branch points in the adult $\alpha \mathrm{ENaC}$ $\mathrm{KO}$ relay cell population resulted in a similar difference in the mean DCl (Fig. 3D). The DCl is a comprehensive measurement of the complexity a cell's dendritic field (see methods for details). The mean ( \pm SEM) $\mathrm{DCl}$ in relay cells in adult $\alpha \mathrm{ENaC} \mathrm{KO}$ mice $(7692.13 \pm 1032.6)$ was 2.3$2.8 \times$ larger than that of relay cells in P20 control (2716.15 \pm 475.0$)$, adult control $(3314.65 \pm 502.6)$, and P20 $\alpha$ ENaC KO $(2790.28 \pm 501.2)$ mice (Fig. 3D). These differences were statistically significant $\left(F_{(3,253)}=8.84\right.$, $p<0.0001$ ). There were no significant differences among the mean DCl of relay cells from P20 control, adult control, and P2O $\alpha \mathrm{ENaC} \mathrm{KO}$ mice ( $p>0.05$; Fig. $3 D$ ). Figure $3 E$ shows a box and whisker plot comparison of the $\mathrm{DCl}$ for both adult populations of relay cells (P20 populations were not included because of small number of cells labeled in each population). A large majority of relay cells from adult $\mathrm{ENaC} \mathrm{KO}$ mice $(81.5 \%)$ had a $\mathrm{DCl}$ larger than the median $\mathrm{DCl}$ of the adult control population. Calculating the mean dendritic complexity of all neurons from any one mouse shows that while there is variability from animal to animal, the significant differences we report are not driven by a few outliers (Extended Data Fig. 3-1D, Extended Data Fig. 3-2).

\section{Relay cells from adult $\alpha \mathrm{ENaC}$ mice have higher-order dendrites}

The results above suggest that the increased complexity observed in relay cells from adult $\alpha \mathrm{ENaC} \mathrm{KO}$ mice are because of changes in the number and/or length of higher-order dendrites (for illustration of dendritic order, see Fig. 3F). To study this, we calculated the mean frequency (Fig. 3G) and mean dendritic length (Fig. $3 H$ ) of each order of dendrite for each group of cells. Statistical analysis 

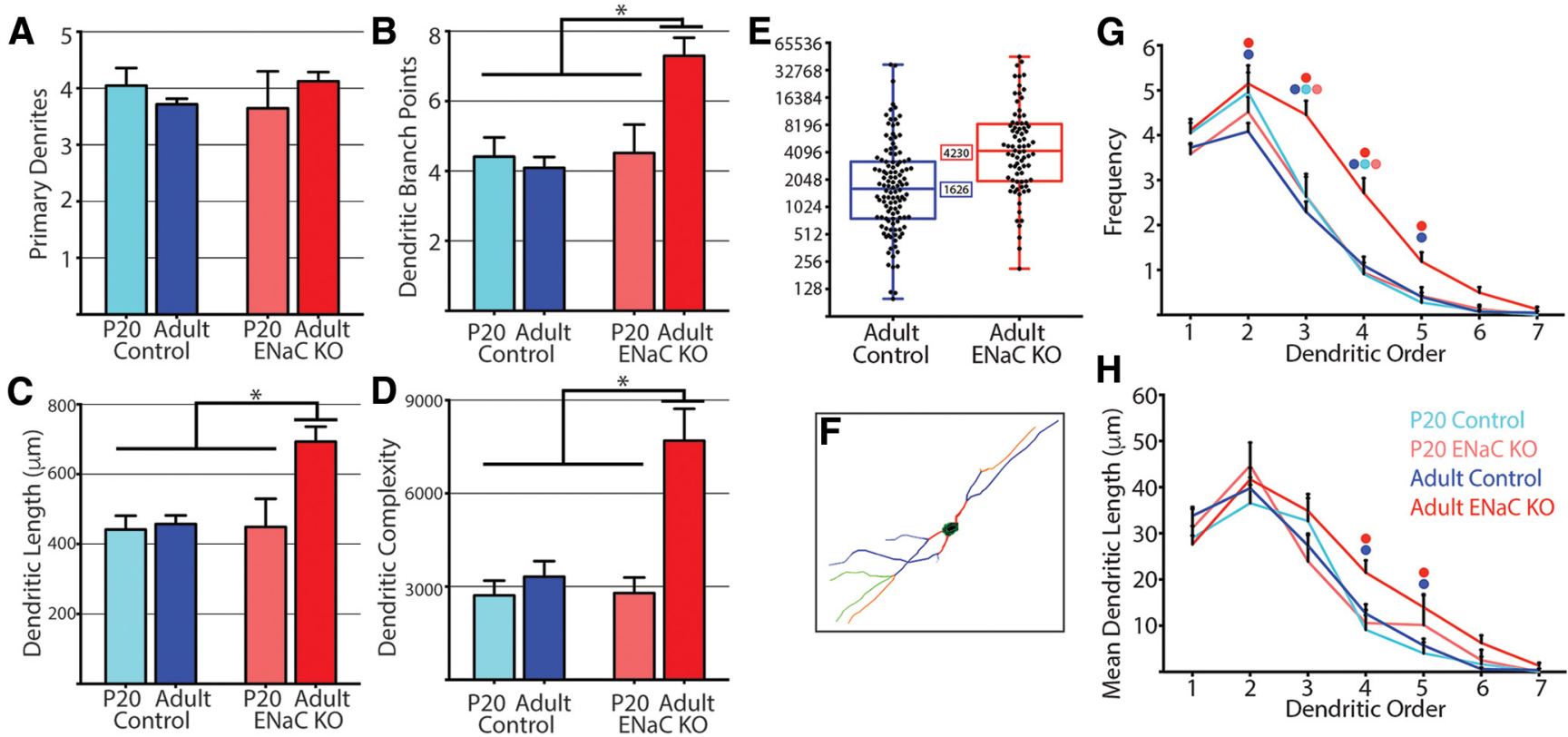

Figure 3. Dendritic characteristics of NST relay cells. $\boldsymbol{A}$, Mean ( \pm SEM) number of primary dendrites in relay cells from P20 control (light blue), adult control (dark blue), P20 ENaC KO (light red), and adult ENaC KO (dark red) mice. $\boldsymbol{B}$, Mean ( \pm SEM) number of dendritic branch points in relay cells from P20 control (light blue), adult control (dark blue), P20 ENaC KO (light red), and adult ENaC KO (dark red) mice. C, Mean ( \pm SEM) total dendritic length $(\mathrm{mm})$ from relay cells from P20 control (light blue), adult control (dark blue), P20 ENaC KO (light red), and adult ENaC KO (dark red) mice. $\boldsymbol{D}$, Mean ( \pm SEM) dendritic complexity (see methods for details) of relay cells from P20 control (light blue), adult control (dark blue), P20 ENaC KO (light red), and adult ENaC KO (dark red) mice. Lines and brackets above $\mathrm{B}, \mathrm{C}$ and $\mathrm{D}$ denote comparisons that reached statistical significance using a one-way ANOVA while correcting for multiple comparisons * $p<0.05$. $E$, Box and whisker plot of dendritic complexity measure for adult control and adult ENaC KO mice, inset box denotes the median for each group of cells. $\boldsymbol{F}$, Diagram illustrating the dendritic order characterization scheme used where primary dendrites are red, second-order dendrites are blue, third-order dendrites are orange, and fourth-order are green. G$H$, Dendritic characteristics by dendritic order. G, Average ( \pm SEM) number of dendrites by dendritic order in relay cells from P20 control (light blue), adult control (dark blue), P20 ENaC KO (light red), and adult ENaC KO (dark red) mice. $\boldsymbol{H}$, Mean ( \pm SEM) dendritic lengths by dendritic order in relay cells from P20 control (light blue), adult control (dark blue), P20 ENaC KO (light red), and adult $\mathrm{ENaC} \mathrm{KO}$ (dark red) mice. Colored circles above each data point denote groups that are significantly different from each other $(p<0.05)$. Also see Extended Data Figures 3-1 and 3-2.

found a significant effect of animal group on mean frequency $\left(F_{(3,1771)}=35.7, p<0.0001\right.$; Table 1$)$ and mean dendritic length $\left(F_{(3,1771)}=5.12, p=0.002\right.$; Table 1$)$.

Consistent with what was reported above, there were no differences in the mean number of primary dendrites among neurons from P20 control, adult control, P20 $\alpha \mathrm{ENaC} \mathrm{KO}$, and adult $\alpha \mathrm{ENaC} \mathrm{KO}$ mice (Fig. 3E; Table 1). There were also no differences in the mean dendritic lengths of primary dendrites among neurons in P20 control, adult control, P20 $\alpha \mathrm{ENaC} \mathrm{KO}$, or adult $\alpha \mathrm{ENaC} \mathrm{KO}$ mice (Fig. 3F; Table 1).

As was predicted, the Bonferroni post hoc test found that relay cells from adult $\alpha \mathrm{ENaC} \mathrm{KO}$ mice had significantly more second-order $(1.26 \times)$, third-order $(1.94 \times)$, fourth-order $(2.47 \times)$, and fifth-order $(2.98 \times)$ dendrites than cells from adult control mice (Fig. 3G; Table 1). However, the mean dendritic lengths of these dendritic groups were only significantly different when comparing fourth and fifth-order dendrites (Fig. $3 H$; Table 1). Fourth-order and fifth-order dendrites were $1.70 \times$ and $2.46 \times$ longer in cells from adult $\alpha \mathrm{ENaC} \mathrm{KO}$ mice than in cells from adult control mice. The mean dendritic length of third-order dendrites between adult $\alpha \mathrm{ENaC} \mathrm{KO}$ and control mice was just above the threshold for significance (Table 1).

Adult $\alpha \mathrm{ENaC} \mathrm{KO}$ mice also had more third-order and fourth-order dendrites than both the P20 control (1.79x and $2.99 \times$, respectively) or P2O $\alpha \mathrm{ENaC} \mathrm{KO}(1.69 \times$ and $2.90 \times$, respectively) populations (Fig. 3G; Table 1). The mean dendritic lengths of these dendrites were not significantly different between any of these groups (Fig. 3H; Table 1).

There were no differences in the frequency or mean dendritic lengths associated with sixth-order or seventhorder dendrites among any groups of relay cells (Fig. 3G, $H$; Table 1). This was due, in part, to very few cells having sixth-order or seventh-order dendrites, regardless of group.

\section{Gross dendritic morphology and orientation of relay cells from adult $\alpha \mathrm{ENaC} \mathrm{KO}$ mice appear normal despite increased dendritic complexity}

To assess how the increased dendritic complexity observed in relay cells from adult $\alpha \mathrm{ENaC} \mathrm{KO}$ mice affected the overall dendritic morphology, we computed a Sholl 
Table 1: Significant results

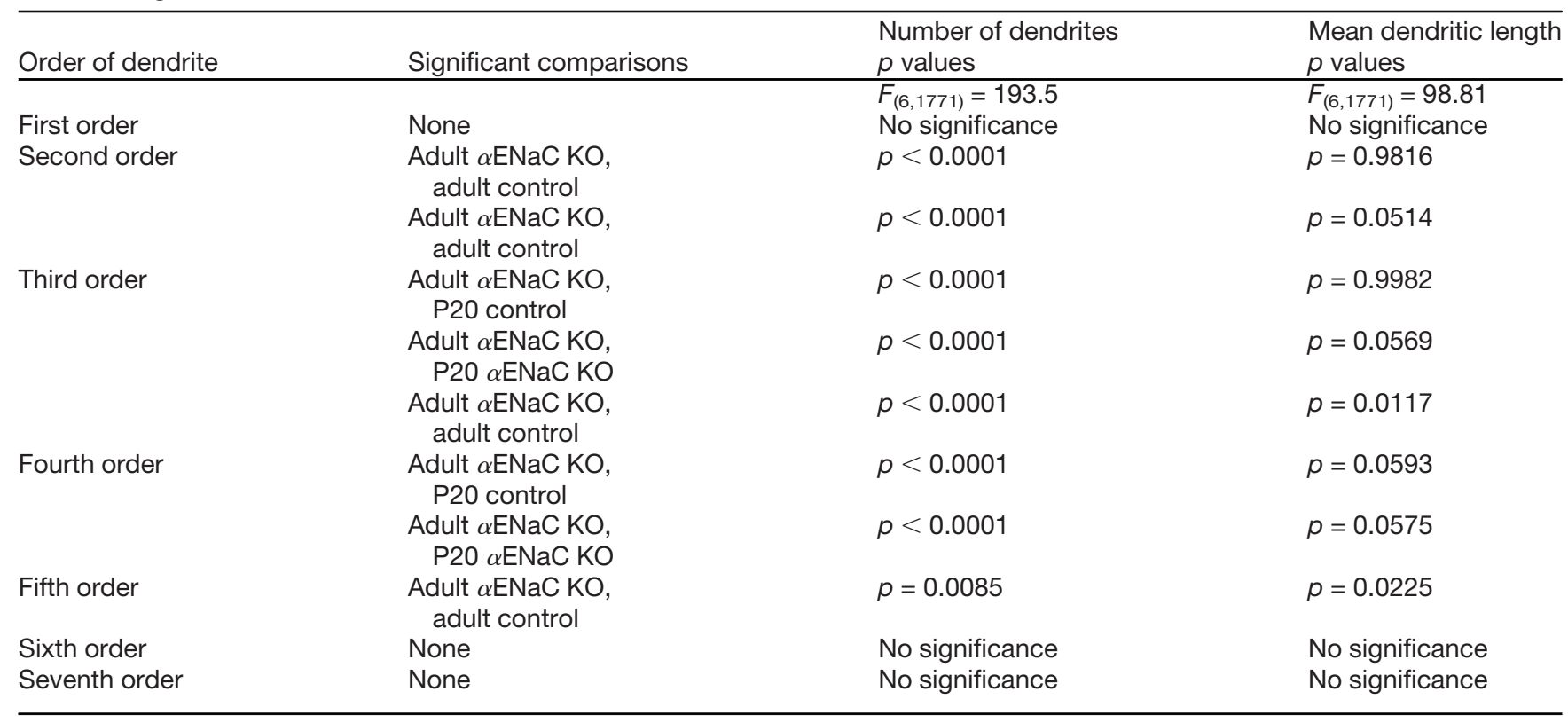

analysis (for details, see Materials and Methods; Fig. $\left.4 A^{\prime}\right)$. Briefly, Sholl analyses use a series of concentric circles, centered on the cell soma, to assess how dendritic architecture changes as the dendrites extend from the cell soma (Fig. 4A'). The number of times dendrites intersect with each concentric circle (Fig. 4A) are then collected to assess how the dendritic field is spatially organized.

Figure $4 A$ shows the results from a Sholl analysis, calculating the mean number of times dendritic material intersected with each concentric ring for each group of NST relay cells. As would be predicted from the dendritic complexity results shown above, relay cells in adult $\alpha \mathrm{ENaC} \mathrm{KO}$ mice averaged significantly more dendritic intersections than any other group of relay cells $\left(F_{(3,11887)}=132, p<0.0001\right.$; Fig. 4A). However, these differences were only significant within the first $125 \mu \mathrm{m}$ from the cell soma. Group-related differences were evident at adulthood. The number of dendritic intersections for cells in adult $\alpha$ ENAC $\mathrm{KO}$ mice were significantly greater than that from adult control mice, with differences occurring 20-110 $\mu \mathrm{m}$ from the cell soma $(p<0.05$; Fig. $4 A$ ). Moreover, we found that the number of dendritic intersections increased after P20 in $\alpha \mathrm{ENaC} \mathrm{KO}$ mice, with age-related differences occurring 35-95 $\mu \mathrm{m}$ from the soma ( $p<0.05$; Fig. 4A). Finally, the dendritic intersections of relay cells from the soma of adult $\alpha \mathrm{ENaC} \mathrm{KO}$ mice were significantly greater than from P20 control mice (60-125 $\mu \mathrm{m} ; p<0.05$; Fig. 4A). Thus, a majority of the changes in the dendritic architecture seen in adult $\alpha \mathrm{ENaC} \mathrm{KO}$ mice relay cells occurred within the first $125 \mu \mathrm{m}$ from the cell soma.

Interestingly, while relay cells from adult $\alpha \mathrm{ENaC} \mathrm{KO}$ mice had significantly more intersections than that in the adult control mice, the overall shape of the curves created in the Sholl analysis were similar, suggesting that the overall organization of dendrites of these two cell groups were similar, despite the differences in dendritic complexity and dendritic length. Likewise, comparing the shape of both curves from the two P20 groups with that of the adult control group implies that there may be a subtle developmental reorganization of dendritic material. That is, there appears to be a slight loss of dendritic material in the dendritic field closest to the cell soma coupled with a corresponding elaboration of dendritic fields further from the cell soma between P20 and adulthood.

We also asked whether the removing ENaC-mediated taste activity altered the dendritic orientation preference that these NST relay cells maintain. Typically, these relay cells orient their dendritic fields parallel to the solitary tract, the source of gustatory input from the periphery (Davis, 1988; Corson and Erisir, 2013). This results in a dendritic orientation preference that is roughly $30-45^{\circ}$ from the horizontal (medial-lateral) axis. To assess whether ENaC-mediated neural activity impacted this orientation preference, we created polar histograms for each cell group (for details, see Materials and Methods; Fig. $\left.4 B^{\prime}\right)$. Figure $4 B$ shows the resulting normalized polar histograms from each cell group. We found that polar histograms for P20 control and P20 $\alpha \mathrm{ENaC} \mathrm{KO}$ mice were similar to each other and relatively similar to that of the adult control relay cell group (Fig. 4B). Furthermore, both P20 groups and the adult control group had similar dendritic orientation preferences, which was roughly $45^{\circ}$ off the horizontal (medial-lateral). Interestingly, while the adult $\alpha \mathrm{ENaC} \mathrm{KO}$ relay cell polar histogram was larger than all other groups, likely reflecting their increased dendritic lengths, the overall orientation preference of these cells was similar to that of the other three groups (Fig. 4B). Thus, the typical orientation preference that NST relay cells display develops relatively early in an animal's life, before P20, and does not require ENaC-mediated taste activity to occur. 

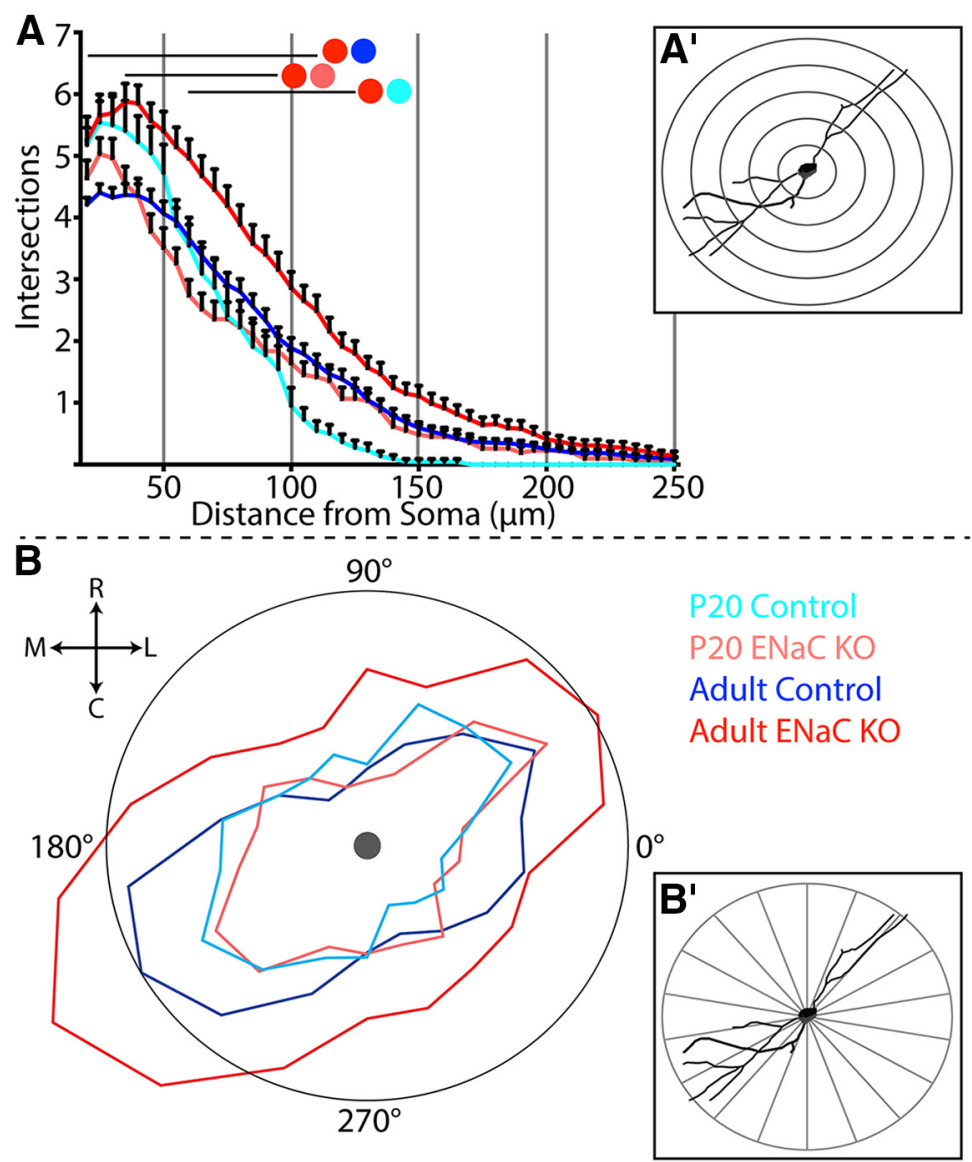

Figure 4. Spatial organization of dendritic fields. $\boldsymbol{A}$, Sholl analysis measuring the number of intersections created by dendrites of NST relay cells from P20 (light blue), adult control (dark blue), P20 ENaC KO (light red), and adult ENaC KO (dark red) mice as dendrites extend away from the cell soma. Colored circles with lines denote areas of significant difference $(p<0.05)$ between two groups. $\boldsymbol{A}^{\prime}$, Representation of how the dendritic field is divided with a sholl analysis. $\boldsymbol{B}, \mathrm{P}$ Polar histogram showing the angular distribution of dendritic material in the horizontal plane of cells from P20 control (light blue), adult control (dark blue), P20 ENaC KO (light red), and adult ENaC KO (dark red) mice. Area around the cell soma (grey circle) was divided into $20^{\circ}$ bins as depicted in $\boldsymbol{B}^{\prime}$. The total amount of dendritic material within each $20^{\circ}$ bin was measured for each cell and then averaged across each cell group. Mean dendritic lengths for each group within each $20^{\circ}$ bin are represented on a relative scale by the distance each point is from the center of the soma. The adult control bin with the largest mean dendritic length $\left(200-220^{\circ}\right)$ was used to normalize all of the other data points. Thus, the black circle represents a normalization ratio of 1 . R, rostral; C, caudal; L, lateral; M, medial.

\section{CT terminal fields develop abnormally and do not "prune" in adult $\alpha \mathrm{ENaC} \mathrm{KO}$ mice}

We previously reported that ENaC-mediated taste activity is necessary for both the development and maintenance of gustatory terminal fields in the NST (Skyberg et al., 2017; Sun et al., 2017). Gustatory terminal field volumes in adult $\alpha \mathrm{ENaC} \mathrm{KO}$ mice, lacking $\mathrm{ENaC}$-mediated taste activity throughout life, were $\sim 140 \%$ larger than that of adult control mice. However, terminal fields were only analyzed in adult control and $\mathrm{ENaC}-\mathrm{KO}$ mice. Therefore, it is unclear whether the terminal field changes occur before or after P20, when ENaC-mediated taste experience matures. Therefore, to gain an understanding of the developmental trajectory that these terminal fields take in both control and $\alpha \mathrm{ENaC} \mathrm{KO}$ mice, we labeled the CT nerve in $\mathrm{P} 20$ and adult control and $\alpha \mathrm{ENaC} \mathrm{KO}$ mice.

Figure 5 shows representative photomicrographs (Fig. $5 A-D$ ) of the CT as well as quantification of the total CT terminal field volume (Fig. $5 E$ ) for control and $\alpha \mathrm{ENaC} \mathrm{KO}$ mice at the two developmental ages. Statistical analysis confirmed there was a significant difference in the total CT terminal field volume among groups $\left(F_{(3,18)}=42.7\right.$, $p<0.0001$ ). Developmentally, mean CT terminal field volumes in control mice decreased with age (Fig. $5 A, B, E$ ). The CT terminal field volume decreased by $56 \%$ throughout development. This difference was statistically significant $(p<0.0001$; Fig. 5E). This developmental decrease in CT terminal field size was similar that reported in rat (May and Hill, 2006; Mangold and Hill, 2008) and mouse (Zheng et al., 2014). By contrast, the CT terminal field volumes increased between P2O and adulthood in $\alpha \mathrm{ENaC}$ $\mathrm{KO}$ mice. That is, the mean CT terminal field volumes underwent a $33 \%$ increase with age and was statistically significant $(p=0.0084$; Fig. $5 C-E)$. These age-related differences in terminal field development resulted in dramatic differences between controls and $\mathrm{ENaC}-\mathrm{KO}$ mice at adulthood. Terminal field volumes in adult $\alpha \mathrm{ENaC} \mathrm{KO}$ mice were $140 \%$ larger than that found in age-matched 


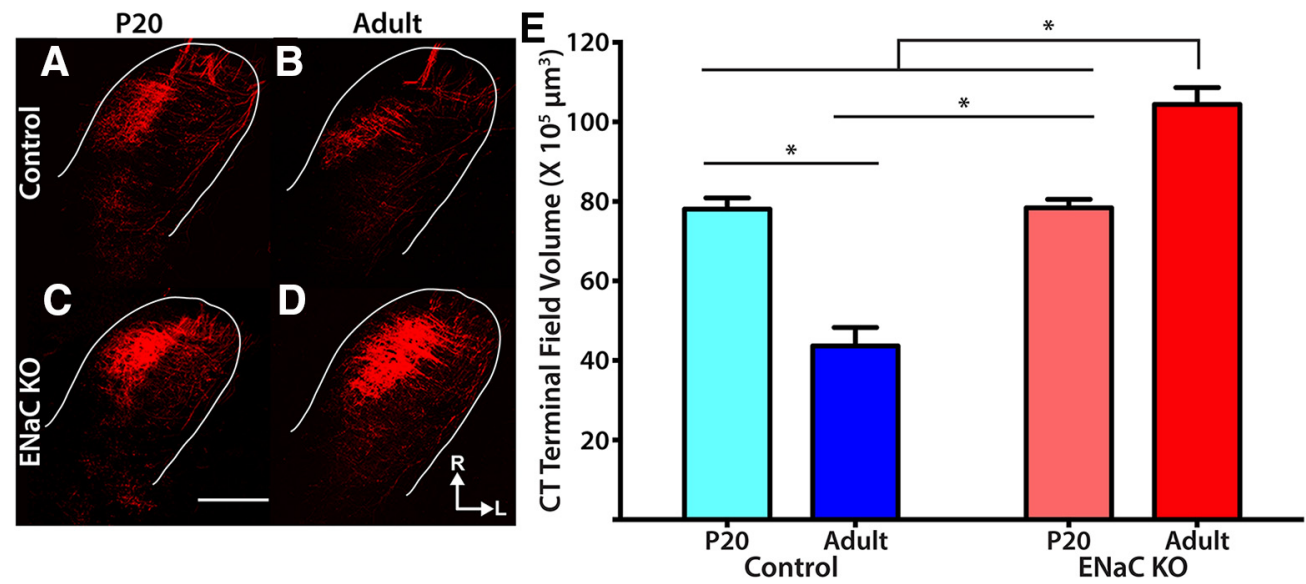

Figure 5. Activity-dependent development of chorda tympani (CT) terminal field. $\boldsymbol{A}-\boldsymbol{D}$, Photomicrographs of the CT terminal field in horizontal sections from a P20 control $(\boldsymbol{A})$, adult control $(\boldsymbol{B}), \mathrm{P} 20 \mathrm{ENaC} \mathrm{KO}(\boldsymbol{C})$, and adult ENaC KO $(\boldsymbol{D})$ mice. White lines in $\boldsymbol{A}-\boldsymbol{D}$ demark the border of the NST. E, Quantification of the total CT terminal field volume in P20 control (light blue), adult control (dark blue), P20 ENaC KO (light red), and adult ENaC KO (dark red) mice. * $p<0.05$. Scale bar in C, $250 \mathrm{~mm}$. R, rostral; L, lateral.

control mice ( $p<0.0001$; Fig. 5E). Interestingly, the mean CT terminal field volumes in P20 control and P20 $\alpha \mathrm{ENaC}$ KO mice were nearly identical $(p>0.9999)$, suggesting these terminal fields develop similarly before P20, indicating that the absence of ENaC-mediated taste activity after P20 does not lead to a failure to develop (i.e., they stay at the immature state) but rather leads to increased growth of the fields.

\section{Adult $\alpha \mathrm{ENaC} \mathrm{KO}$ mice have a loss of ENaC-mediated sodium taste activity throughout development}

Figure 6 shows the integrated (Fig. $6 A-D$ ) and normalized (Fig. 6E,F) CT whole-nerve taste responses to an increasing concentration series of $\mathrm{NaCl}$ in $\mathrm{P} 20$ control (Fig. $6 A, E$ ), adult control (Fig. 6B,E), P20 ENaC KO (Fig. 6C,F), and adult ENaC KO (Fig. $6 D, F$ ) mice. We found a clear developmental increase in the ability of $\mathrm{NaCl}$ to drive CT responses in control mice (Fig. $6 A, B, E$ ). This is particularly evident when comparing CT responses to high concentrations of $\mathrm{NaCl}$. The relative responses to 0.25 and $0.5 \mathrm{M}$ $\mathrm{NaCl}$ in P20 control mice were significantly less (40-50\%) than the respective responses in adult control mice (Fig. $6 E ; \mathrm{t}_{(6)}=2.9-4.9$; significant posttest, $p=0.03$ and 0.005 for $0.25 \mathrm{M} \mathrm{NaCl}$ and $0.5 \mathrm{M} \mathrm{NaCl}$, respectivel). Interestingly, there were also differences in $\mathrm{NaCl}$ responses after lingual application of amiloride between P20 control and adult control mice. Relative CT responses to $0.5 \mathrm{M} \mathrm{NaCl}$ after amiloride from P20 control mice were $50 \%$ less than the respective responses in adult control mice after amiloride $\left(\mathrm{t}_{(6)}=4.2 ; p=0.01\right.$; Fig. $\left.6 E\right)$. Finally, while there is a developmental increase in both the amiloride-sensitive and amiloride-insensitive salt transduction pathways in control mice, the observation that amiloride attenuates $\mathrm{NaCl}$ responses more in adult controls than P20 controls suggests that a majority of this development is ENaC mediated (Fig. 6E). These findings are similar to that reported in rat (Hill and Almli, 1980; Ferrell et al., 1981; Yamada, 1980; Hill and Bour, 1985).

By comparison, conditionally deleting the Scnn1a gene from taste bud cells had selective effects on CT whole- nerve taste responses. Like adult control mice, increasing the concentration of $\mathrm{NaCl}$ in adult $\alpha \mathrm{ENaC} \mathrm{KO}$ mice resulted in increased CT responses; however, the relative magnitude of these responses was lower than that of adult control mice at all stimulus concentrations (Fig. $6 E, F)$. However, the only group-related difference occurred for taste responses to $0.5 \mathrm{M} \mathrm{NaCl}\left(\mathrm{t}_{(6)}=15.0 ; p=\right.$ 0.001 and is similar to that previously reported (Chandrashekar et al., 2010; Skyberg et al., 2017; Sun et al., 2017). Finally, while the average CT responses from P2O control mice are larger than that of P2O ENaC KO mice to any concentration of $\mathrm{NaCl}$, these differences were not statistically significant $(p>0.05$; Fig. $6 E, F)$. This may be due in part to higher variability of P20 control mice responses, potentially reflecting a period of significant sodium taste development.

Importantly, the ENaC blocker, amiloride, did not attenuate CT responses from either P20 ENaC KO or adult $\mathrm{ENaC} \mathrm{KO}$ mice (Fig. $6 C, D, F$ ), indicating two things. First, that removal of the Scnn1a gene was effective in eliminating ENaC-mediated taste activity. And second, the remaining responses in these $\mathrm{ENaC} \mathrm{KO}$ mice were mediated by an amiloride-insensitive transduction pathway(s). Interestingly, both control and $\mathrm{ENaC} \mathrm{KO}$ mice exhibit developmental increases in amiloride-insensitive CT whole-nerve responses between P20 and adulthood (Fig. 6), suggesting there is a postnatal development of the amiloride-insensitive salt transduction pathway in both mouse lines. Multiple studies have shown these amiloride-insensitive salt responses are dependent on the anion component of salts (chloride here; Elliot and Simon, 1990; Formaker and Hill, 1988; Ye et al., 1993; Lewandowski et al., 2016; Roebber et al., 2019). However, the transduction pathway(s) responsible for these anion responses are not as well understood. Lewandowski et al. (2016) suggest type 3 taste bud cells gate this amiloride-insensitive pathway, while Roebber et al. (2019) find a subset of type 2 taste bud cells to be responsible. Similarly, the receptor(s) mediating these amiloride-insensitive 
A

B
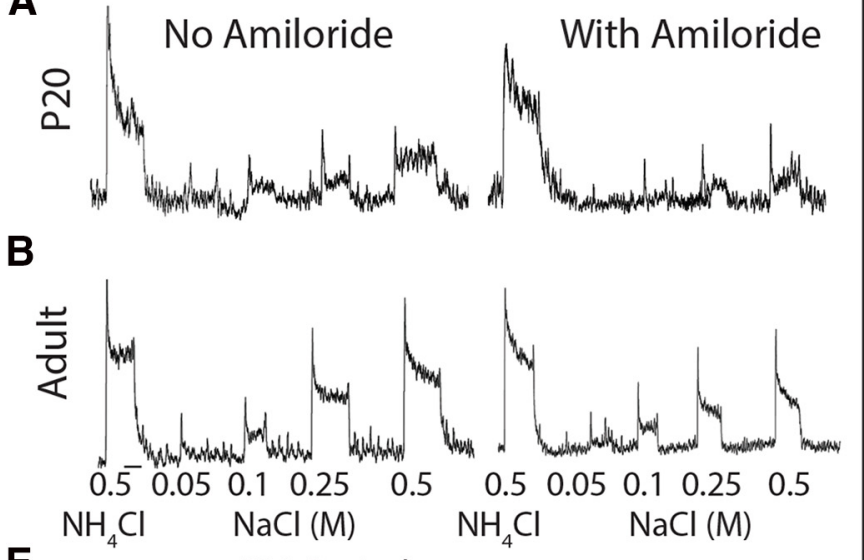

lc

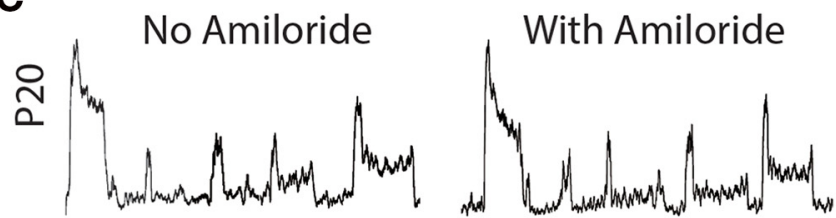

D

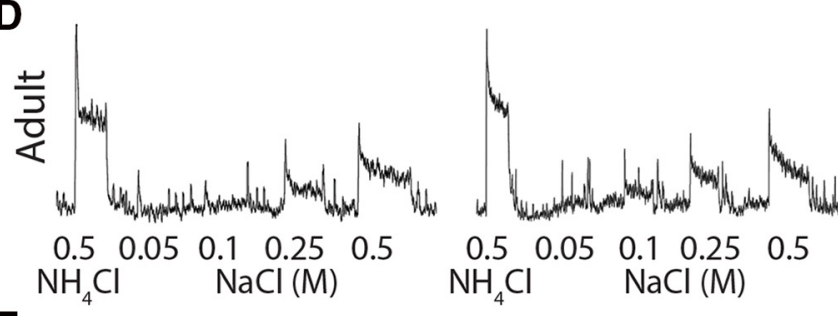

E

$\mathbf{F}$
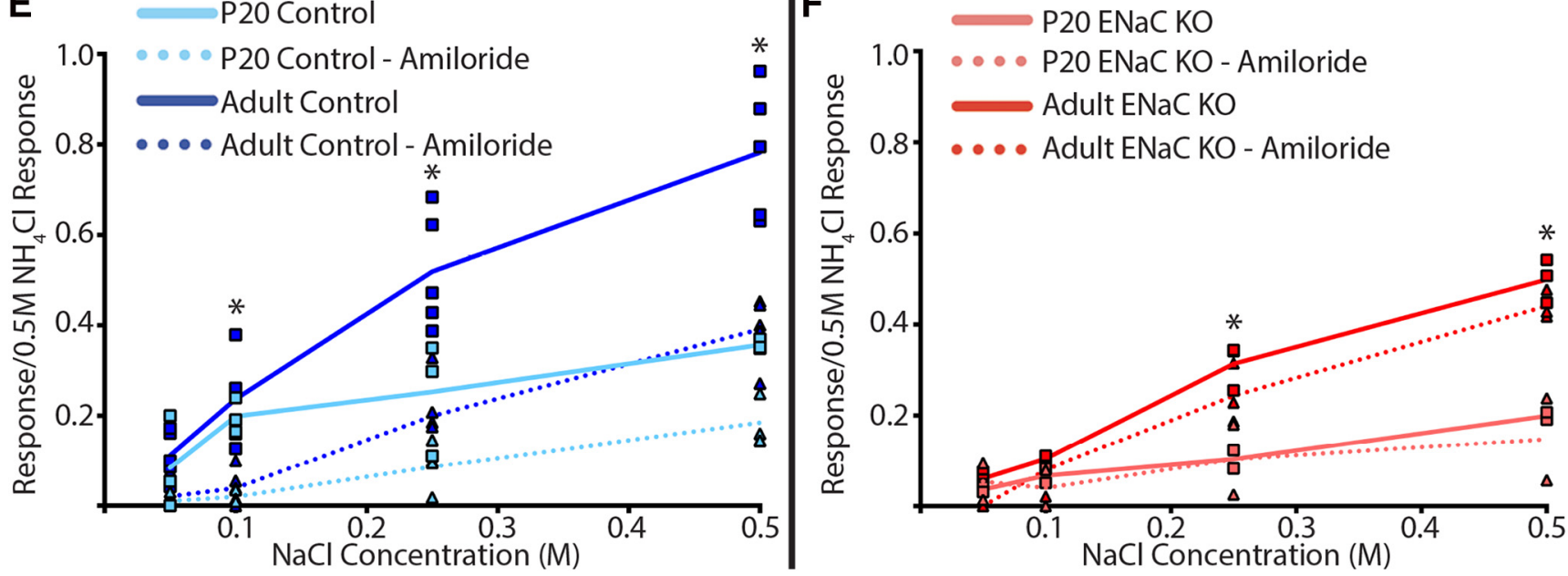

Figure 6. Development of chorda tympani (CT) whole nerve responses in control (left panel) and ENaC KO mice (right panel). $\boldsymbol{A}$, Integrated CT taste responses from a P20 control mouse to $0.5 \mathrm{M} \mathrm{NH} 4 \mathrm{Cl}$ and an increasing concentration series of $\mathrm{NaCl}(0.05,0.1$, $0.25,0.5 \mathrm{M})$ before and after lingual application of ENaC blocker, amiloride. $\boldsymbol{B}$, Same as A but from an adult control mouse. C, Integrated CT taste responses from a P20 ENaC KO mouse to $0.5 \mathrm{M} \mathrm{NH} 4 \mathrm{Cl}$ and an increasing concentration series of $\mathrm{NaCl}(0.05$, $0.1,0.25,0.5 \mathrm{M})$ before and after lingual application of ENaC blocker, amiloride. $\boldsymbol{D}$, Same as $\mathrm{C}$ but from an adult ENaC KO mouse. Scale bar in $\boldsymbol{B}, 20$ s and applies to $\boldsymbol{A}-\boldsymbol{D}$. $\boldsymbol{E}$, Mean Relative taste responses from P20 control mice (light blue) and adult control mice (dark blue) to a concentration series of $\mathrm{NaCl}$ before (solid lines) and after (dotted lines) lingual application of amiloride. Responses from individual animals before amiloride are represented by squares while responses after amiloride are represented with triangles. $\boldsymbol{F}$, Mean relative taste responses from P20 ENaC KO mice (light red) and adult ENaC KO mice (dark red) to a concentration series of $\mathrm{NaCl}$ before (solid lines) and after (dotted lines) lingual application of amiloride. Responses from individual animals before amiloride are represented by squares while responses after amiloride are represented with triangles. ${ }^{*} p<0.05$.

responses area also not well characterized. Regardless of the exact mechanisms, the observation that amilorideinsensitive responses develop postnatally is novel and raises interesting questions regarding the molecular/ cellular changes underlying this development.

In summary, between P20 and adulthood, there is an $\mathrm{ENaC}$-mediated developmental increase in the ability of $\mathrm{NaCl}$ to drive whole-nerve responses in control mice (Fig. $6 E$ ). Removal of the Scnn1a gene in our ENaC KO mice prevented this developmental increase after P20 in the amiloride-sensitive CT responses and prevented sodium-elicited taste activity from entering the central gustatory system (Fig. 6F). Finally, we found that there may also be a similar developmental change in the amiloride-insensitive pathway in both control and $\mathrm{ENaC} \mathrm{KO}$ mice (Fig. 6E,F).

\section{Discussion}

Removal of ENaC-mediated taste activity throughout life had significant effects on the development and maintenance of gustatory circuits in the mouse NST. Here, we show that the enlarged dendritic fields of gustatory relay neurons in the NST of adult $\alpha \mathrm{ENaC} \mathrm{KO}$ mice parallel that found for the terminal fields of gustatory nerves that make their inputs onto these neurons. Moreover, the substantial age-related changes in terminal and dendritic field size in $\mathrm{ENaC}$ KO mice occur after P20, an age when ENaC-mediated peripheral taste responses begin to mature in normally-developing mice. These data suggest that there is a period of considerable reorganization in central gustatory circuity after P20 in both control mice with normal taste experience and $\mathrm{ENaC} \mathrm{KO}$ mice lacking sodium taste experience. However, the direction of these changes was 
opposite: terminal field sizes in control mice decreased throughout early postnatal development while terminal fields and dendritic fields in $\mathrm{ENaC} \mathrm{KO}$ mice increased in size. Collectively, these data are consistent with the hypothesis that peripheral taste-elicited activity short-circuits the default program driving expansion of gustatory nerve terminal fields and the dendrites of first-order central neurons that they innervate.

\section{Development of the first central gustatory synaptic relay in control mice}

In control mice, terminal fields of gustatory afferents undergo extensive changes in size after P20. Between P15 and adulthood the CT terminal field reorganizes, resulting in a twofold decrease in terminal field volume (Fig. 5; Zheng et al., 2014). Around P30 these terminal fields reach a mature organization and are maintained throughout the animal's life (Zheng et al., 2014). This developmental period coincides with an increase in taste response magnitudes (particularly to $\mathrm{NaCl}$ ) in these same nerves. Interestingly, the postsynaptic dendritic fields appear fully mature well before the presynaptic terminal fields have begun their apparent activity-dependent reorganization. While a causal relationship between the development of presynaptic and postsynaptic elements of this circuit is not readily apparent, understanding changes at the synaptic level may provide useful. Wang et al. (2012) found an age-dependent decrease in the number of CT terminal synapses in the rat NST, as would be predicted by the developmental decreases in total CT terminal field volume in rat (May and Hill, 2006; Mangold and Hill, 2008) and mouse (Fig. 5; Zheng et al., 2014). Interestingly, they report a substantial developmental decrease in number of CT synapses onto GABAergic targets (Wang et al., 2012). There is also evidence that the decrease in terminal field size and numbers of synapses are paradoxically accompanied by an age-related increase in functional taste responses from the NST, especially to $\mathrm{NaCl}$ (Hill et al., 1983). Therefore, terminal field pruning throughout development may, in part, reflect synaptic reorganization away from GABAergic targets and toward NST relay cells. Future research measuring changes in the number, location, and strength of gustatory synapses onto NST relay cells will provide useful in further understanding the postnatal development of this circuit.

\section{Development of the first central gustatory synaptic relay in $\alpha \mathrm{ENaC} \mathrm{KO}$ mice}

Removal of ENaC-mediated sodium taste activity, beginning embryonically and continuing throughout development had multiple effects on the postnatal organization of gustatory circuits in the NST. CT terminal fields in $\mathrm{ENaC} \mathrm{KO}$ mice not only failed to prune but, instead, expanded in volume into adulthood. It is not clear whether the lack of change in peripheral input around P20 in our $\mathrm{ENaC} \mathrm{KO}$ mice may be driving this abnormal growth in terminal and dendritic fields or simply coincides with this dendritic expansion. Regardless of the specific mechanism, it is possible that the wholesale anatomic changes

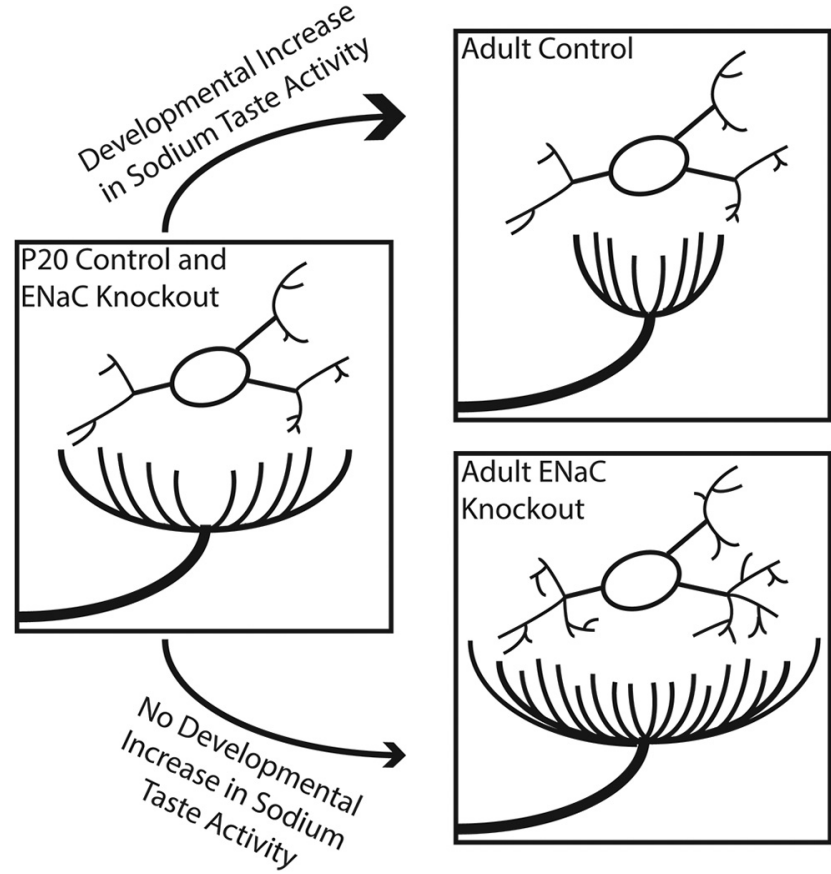

Figure 7. Summary figure illustrating the development of gustatory NST circuitry in control and ENaC KO mice between P2O and adulthood. In control mice, the developmental increase in sodium-taste activity drives pruning of terminal fields but does not alter NST relay cell architecture. Conversely, in ENaC KO mice that lack sodium-taste responses throughout life, gustatory terminal fields not only fail to prune but get larger. NST relay cell dendrites also became more elaborate in ENaC KO mice. Importantly, there were no differences between P20 control and P20 ENaC KO mice in terminal field size or measures of dendritic architecture.

could produce profound changes in taste-related function and behavior. For example, Chandrashekar et al. (2010) report that taste-related behaviors are largely the same between ENaC KO and control mice, with the exception of responses to appetitive concentrations of $\mathrm{NaCl}$. Specifically, it appears as though appetitive aspects of $\mathrm{NaCl}$ in salt appetite are blunted or eliminated in these mice, the normal avoidance of high concentrations of $\mathrm{NaCl}$ are left intact. Moreover, our findings here suggest a significant alteration in the way that brainstem taste neurons will process (i.e., code) taste stimuli.

\section{Role of ENaC-mediated activity in development and maintenance of the first central gustatory synaptic relay}

The results from these and other experiments illustrate multiple effects of removing ENaC-mediated sodium taste activity throughout an animal's life. Indeed, the effects of removing $\mathrm{ENaC}$ activity on the terminal and dendritic fields were not identical. In the case of the terminal fields of gustatory afferents, the normal developmental decrease in terminal field size was prevented in ENaC KO mice, suggesting that sodium salt activity can drive this developmental pruning of terminal fields in the NST (Fig. 7; Sun et al., 2017). We have also shown that the maintenance of mature terminal 
fields is dependent on ENaC-mediated sodium taste activity, without which terminal fields revert back to an immature, enlarged organization (Skyberg et al., 2017). By contrast, the dendritic fields show a different dependence on this ENaC-elicited taste activity. Because the dendritic fields resemble a mature organization by P20 in control mice, which is before ENaC-mediated activity has fully matured, it is unlikely that this reorganization is driven by $\mathrm{ENaC}$ activity. However, similar to terminal fields, the maintenance of NST dendritic fields after P20 appears dependent on ENaCmediated sodium taste activity (Figs. 3, 7). Therefore, while there are differences in the specific ways ENaC activity modulates the presynaptic and postsynaptic elements of the gustatory NST circuit, removing this activity always results in an elaboration of the elements within this circuit (Fig. 7; Skyberg et al., 2017; Sun et al., 2017). One intriguing explanation for this observation is that dendritic and axonal elongation are the default growth patterns for these gustatory cells and neuronal activity attenuates this innate program. In fact, this has been proposed to occur during the morphologic development of retinogeniculate axons in the dLGN (Sretavan et al., 1988) as well as during dendritic development of Purkinje cells in the murine cerebellum (Schilling et al., 1991).

\section{The specificity of altered NST cells}

One unique benefit of using $\alpha \mathrm{ENaC} \mathrm{KO}$ mice as a model to assess the roles neural activity plays in the development and organization of gustatory circuitry is that these mice only lack taste activity from a single transduction pathway (salty; Chandrashekar et al., 2010; Skyberg et al., 2017; Sun et al., 2017). Given the specificity of our functional $\mathrm{KO}$ in the periphery, one may expect the central effects to exhibit some specificity as well. Put more simply, if we are only removing sodium salt taste, are we also only altering one subgroup of NST relay cells? While it is impossible to determine this conclusively without also knowing the taste response profiles of each of these cells, analysis of the dendritic complexity across adult control and $\mathrm{ENaC} \mathrm{KO}$ populations is consistent with the idea that dendritic growth occurs in a majority of cells rather than one subpopulation. That is, $81.5 \%$ of ENaC KO cells (66 out of 81 ) had dendritic complexity measures larger than the median dendritic complexity of the adult control sample (Fig. 3E). Furthermore, plotting box and whisker plots for the dendritic complexity of each population shows that both the lower and upper quartile, as well as the range, are substantially higher in the adult ENaC population when compared with the adult control population (Fig. 3E). This is consistent with a wholesale increase in dendritic complexity rather than an increase in only one subpopulation of cells. Finally, it has been reported that the majority of rodent NST relay cells are generally broadly tuned and respond to more than one taste stimuli, indicating there may not be a large number of physiologically defined subpopulations of NST relay cells that would be specifically affected by deletion of peripheral sodium salt taste (Hill et al., 1983; Sato and Beidler, 1997; Cho et al., 2002; Carleton et al., 2010). However, a recent study has shown a population of NST relay cells that selectively respond to sour stimuli (Zhang et al., 2019), suggesting there may be subpopulation of neurons in our data that are unaffected by the functional removal of $\mathrm{ENaC}$.

\section{Conclusion}

We show here that removal sodium salt taste beginning embryonically and continuing throughout development had large effects on the development and organization of gustatory circuits in the NST. Both gustatory afferent terminal fields and the dendritic fields of NST relay cells were significantly larger in adult ENaC KO mice than in agematched controls. Furthermore, the effects of removing sodium taste responses did not occur until after P20, which is when functional taste responses in control mice increase in magnitude. Collectively, these data suggest the earliest central synaptic relay in the gustatory system is plastic late into development and the normal formation of these circuits is directed by sufficient amounts of neural inputs that relate to sodium salt taste.

\section{References}

Armstrong RA (2014) When to use the Bonferroni correction. Ophthalmic Physiol Opt 34:502-508.

Brunjes P (1994) Unilateral naris closure and olfactory system development. Brain Res Rev 19:146-160.

Cang J, Rentería RC, Kaneko M, Liu X, Copenhagen DR, Stryker MP (2005) Development of precise maps in visual cortex requires patterned spontaneous activity in the retina. Neuron 48:797-809.

Carleton A, Accolla R, Simon S (2010) Coding in the mammalian gustatory system. Trends Neurosci 33:326-334.

Chandrashekar J, Kuhn C, Oka Y, Yarmolinsky DA, Hummler E, Ryba NJP, Zuker CS (2010) The cells and peripheral representation of sodium taste in mice. Nature 464:297-301.

Cho YK, Li CS, Smith DV (2002) Taste responses of neurons in the hamster solitary nucleus are modulated by the central nucleus of the amygdala. J Neurophysiol 88:2979-2992.

Corson SL, Hill DL (2011) Chorda tympani nerve terminal field maturation and maintenance is severely altered following changes to gustatory nerve input to the nucleus of the solitary tract. J Neurosci 31:7591-7603.

Corson JA, Erisir A (2013) Monosynaptic convergence of chorda tympani and glossopharyngeal afferents onto ascending relay neurons in the nucleus of the solitary tract: a high-resolution confocal and correlative electron microscopy approach. J Comp Neurol 521:2907-2926.

Davis BJ (1988) Computer-generated rotation analyses reveal a key three-dimensional feature of the nucleus of the solitary tract. Brain Res Bull 20:545-548.

Davis BJ, Jang T (1988) A Golgi analysis of the gustatory zone of the nucleus of the solitary tract in the adult hamster. J Comp Neurol 278:388-396.

Elliot EJ, Simon SA (1990) The anion in salt taste: a possible role for paracellular pathways. Brain Res 535:9-17.

Erickson RP (1966) Nontraumatic headholders for mammals. Physiol Behav 1:97-98.

Fekete Z, Pálfi E, Márton G, Handbauer M, Bérces Z, Ulbert I, Pongrácz A, Négyessy $L$ (2015) In vivo iontophoretic BDA injection through a buried microfluidic channel of a neural multielectrode. Procedia Eng 120:464-467.

Ferrell MF, Mistretta CM, Bradley RM (1981) Development of chorda tympani taste responses in rat. J Comp Neurol 198:37-44.

Formaker BK, Hill DL (1988) An analysis of residual $\mathrm{NaCl}$ taste response after amiloride. American Journal of Physiology 255:10021007. 
Friedlander MJ, Stanford LR, Sherman SM (1982) Effects of monocular deprivation on the structure-function relationship of individual neurons in the cat's lateral geniculate nucleus. J Neurosci 2:321330.

Ganchrow D, Ganchrow JR, Cicchini V, Bartel DL, Kaufman D, Girard D, Whitehead MC (2014) Nucleus of the solitary tract in the C57BL/6J mouse: subnuclear parcellation, chorda tympani nerve projections, and brainstem connections. J Comp Neurol 522: $1565-1596$.

Guido W (2008) Refinement of the retinogeniculate pathway. J Physiol 586:4357-4362.

Hellekant G, af Segerstad $\mathrm{CH}$, Roberts $\mathrm{T}$, van der Wel H, Brouwer JN, Glaser D, Haynes R, Eichberg JW (1985) Effects of gymnemic acid on the chorda tympani proper nerve responses to sweet, sour, salty and bitter taste stimuli in the chimpanzee. Acta Physiol Scand 124:399-408.

Hill DL (1988) Development of chorda tympani nerve responses in the hamster. J Comp Neurol 268:346-356.

Hill DL, Almli CR (1980) Ontogeny of chorda tympani nerve responses to gustatory stimuli in the rat. Brain Research 197: 27-38.

Hill DL, Bour TC (1985) Addition of functional amiloride-sensitive components to the receptor membrane: a possible mechanism for altered taste responses during development. Dev Brain Res 20:310-313.

Hill DL, Bradley RM, Mistretta CM (1983) Development of taste responses in rat nucleus of solitary tract. J Neurophysiol 50:879895.

Hooks BM, Chen C (2006) Distinct roles for spontaneous and visual activity in remodeling of the retinogeniculate synapse. Neuron 52:281-291.

Kaneko T, Saeki K, Lee T, Mizuno N (1996) Improved retrograde axonal transport and subsequent visualization of tetramethylrhodamine (TMR)-dextran amine by means of an acidic injection vehicle and antibodies against TMR. J Neurosci Methods 65:157165.

Katz L, Shatz CJ (1996) Synaptic activity and the construction of cortical circuits. Science 274:1133-1138.

King C, Hill DL (1991) Dietary sodium chloride deprivation throughout development selectively influences the terminal field organization of gustatory afferent fibers projecting to the rat nucleus of the solitary tract. J Comp Neurol 303:159-169.

Krimm RF, Hill DL (1997) Early prenatal critical period for chorda tympani nerve terminal field development. J Comp Neurol 378:254264.

Lasiter PS, Wong DM, Kachele DL (1989) Postnatal development of the rostral solitary nucleus in rat: dendritic morphology and mitochondrial enzyme activity. Brain Res Bull 22:313-321.

Lasiter PS, Kachele DL (1990) Effects of early postnatal receptor damage on development of gustatory recipient zones within the nucleus of the solitary tract. Brain Res Dev Brain Res 55:57-71.

Lasiter PS (1991) Effects of early postnatal receptor damage on dendritic development in gustatory recipient zones of the rostral nucleus of the solitary tract. Brain Res Dev Brain Res 61:197-206.

Leake P, Hradek G, Chair L, Snyder R (2006) Neonatal deafness results in degraded topographic specificity of auditory nerve projections to the cochlear nucleus in cats. J Comp Neurol 497:13-31.

Lee LJ, Lo FS, Erzurumlu R (2005) NMDA receptor-dependent regulation of axonal and dendritic branching. J Neurosci 25:23042311.

Lewandowski BC, Sukumaran SK, Margolskee RF, Bachmanov AA (2016) Amiloride-insensitive salt taste is mediated by two populations of type III taste cells with distinct transduction mechanisms. J Neurosci 36:1942-1953.

Mangold JE, Hill DL (2008) Postnatal reorganization of primary afferent terminal fields in the rat gustatory brainstem is determined by prenatal dietary history. J Comp Neurol 509:594-607.
May O, Hill DL (2006) Gustatory terminal field organization and developmental plasticity in the nucleus of the solitary tract revealed through triple fluorescence labeling. J Comp Neurol 497:658-669.

Norgren R, Leonard CM (1971) Taste pathways in in rat brainstem. Science 173:1136-1139.

Norgren R, Pfaffmann C (1975) The pontine taste area in the rat. Brain Res 91:99-117.

Pillai AG, de Jong D, Kanatsou S, Krugers $H$, Knapman A, Heinzmann JM, Holsboer F, Landgraf R, Joëls M, Touma C (2012) Dendritic morphology of hippocampal and amygdalar neurons in adolescent mice is resilient to genetic differences in stress reactivity. PLoS One 7:e38971.

Reiner A, Veenman CL, Medina L, Jiao Y, Del Mar N, Honig MG (2000) Pathway tracing using biotinylated dextran amines. J Neurosci Methods 103:23-37.

Roebber JK, Roper SD, Chaudhari N (2019) The role of the anion in salt $(\mathrm{NaCl})$ detection by mouse taste buds. J Neurosci 39:62246232.

Sato T, Beidler LM (1997) Broad tuning of rat taste cells for four basic taste stimuli. Chem Senses 22:287-293.

Schilling K, Dickinson MH, Connor JA, Morgan JI (1991) Electrical activity in cerebellar cultures determines Purkinje cell dendritic growth patterns. Neuron 7:891-812.

Shingai T, Beidler LM (1985) Response characteristics of three taste nerves in mice. Brain Res 335:245-249.

Sholl D (1956) Dendritic organization in the neurons of the visual and motor cortices of the cat. J Anat 87:387-406.1.

Skyberg R, Sun C, Hill DL (2017) Maintenance of mouse gustatory terminal field organization is disrupted following selective removal of peripheral sodium salt taste activity at adulthood. J Neurosci 37:7619-7630.

Sollars SI, Walker BR, Thaw a. K, Hill DL (2006) Age-related decrease of the chorda tympani nerve terminal field in the nucleus of the solitary tract is prevented by dietary sodium restriction during development. J Neurosci 137:1229-1236.

Spector AC, Travers SP (2005) The representation of taste quality in the mammalian nervous system. Behav Cogn Neurosci Rev 4:143-191.

Spector AC, Glendinning Jl (2009) Linking peripheral taste processes to behavior. Curr Opin Neurobiol 19:370-377.

Sretavan DW, Shatz CJ, Stryker MP (1988) Modification of retinal ganglion cell axon morphology by prenatal infusion of tetrodotoxin. Nature 336:468-471.

Stellwagen D, Shatz CJ (2002) An instructive role for retinal waves in the development of retinogeniculate connectivity. Neuron 33:357367.

Sun C, Dayal A, Hill DL (2015) Expanded terminal fields of gustatory nerves accompany embryonic BDNF overexpression in mouse oral epithelia. J Neurosci 35:409-421.

Sun C, Hummler E, Hill DL (2017) Selective deletion of sodium salt taste during development leads to expanded terminal fields of gustatory nerves in the adult mouse nucleus of the solitary tract. $\mathrm{J}$ Neurosci 37:660-672.

Tokita K, Boughter JD (2016) Topographic organizations of taste-responsive neurons in the parabrachial nucleus of C57BL/6J mice: an electrophysiological mapping study. J Neurosci 316:151-166.

Tokita K, Inoue T, Boughter JD (2009) Afferent connections of the parabrachial nucleus in C57BL/6J mice. J Neurosci 161:475-488.

Wang S, Corson J, Hill D, Erisir A (2012) Postnatal development of chorda tympani axons in the rat nucleus of the solitary tract. $\mathrm{J}$ Comp Neurol 520:3217-3235.

Whitehead MC (1988) Neuronal architecture of the nucleus of the solitary tract in the hamster. J Comp Neurol 276:547-572.

Whitehead MC (1990) Subdivisions and neuron types of the nucleus of the solitary tract that project to the parabrachial nucleus in the hamster. J Comp Neurol 301:554-574.

Wiesel TN, Hubel DH (1963) Effects of visual deprivation on morphology and physiology of cells in the cat's lateral geniculate body. $J$ Neurophysiol 26:978-993. 
Yamada T (1980) Chorda tympani responses to gustatory stimuli in developing rats. Jpn J Physiol 30:631-643.

Ye Q, Heck GL, DeSimone JA (1993) Voltage dependence of the rat chorda tympani response to $\mathrm{Na}+$ salts: implications for the functional organization of taste receptor cells. J Neurophysiol 70: 167-178.
Zhang J, Jin H, Zhang W, Ding C, O'Keeffe S, Ye M, Zuker C (2019) Sour sensing from the tongue to the brain. Cell 179:392-402.

Zheng S, Sun C, Hill DL (2014) Postnatal reorganization of primary gustatory afferent termnial fields in the mouse brainstem is altered by prenatal dietary sodium history. Abstract: Society for Neurosciences. 